Final version published in American Sociological Review

https://doi.org/10.1177/00031224211033582

\title{
The Intersection of Racial and Gender Attitudes, 1977 through 2018
}

\author{
William J. Scarborough, ${ }^{1}$ Joanna R. Pepin, ${ }^{2}$ Danny L. Lambouths III, ${ }^{3}$ Ronald Kwon, ${ }^{4}$ and \\ Ronaldo Monasterio ${ }^{5}$
}

\begin{abstract}
Intersectionality scholars have long identified dynamic configurations of race and gender ideologies. Yet, survey research on racial and gender attitudes has tended to treat these components as independent. We apply latent class analysis to a set of racial and gender attitude items from the General Social Survey (1977 — 2018) to identify four configurations of individuals' simultaneous views on race and gender. Two of these configurations hold unified progressive or regressive racial and gender attitudes. Two additional formations have discordant racial and gender attitudes where progressive views on one aspect combine with regressive views on the other. In the majority of survey years, the most commonly held configuration endorsed gender equality but espoused new racialist views that attributed racial disparities to cultural deficiencies. This perspective has become increasingly common since 1977 and is most prevalent among White women and White men, likely due to racial-group interest. Black women and Black men, in contrast, are more likely to embrace progressive racial and gender attitudes. We argue that White men's gender egalitarianism may be rooted in self-interest, aimed to acquire resources through intimate relationships. Among Black men, progressive racial and gender attitudes form a necessary coalition with Black women to challenge racism.
\end{abstract}

Keywords: Racial Attitudes, Gender Attitudes, Intersectionality, Public Opinion

${ }^{1}$ University of North Texas, William.Scarborough@unt.edu

${ }^{2}$ State University of New York at Buffalo, jpepin@buffalo.edu

${ }^{3}$ University of Illinios at Chicago, dlambo2@uic.edu

${ }^{4}$ University of North Texas, Ronald.Kwon@unt.edu

${ }^{5}$ University of North Texas, Ronaldo.Monasterio@unt.edu 


\section{The Intersection of Racial and Gender Attitudes, 1977 through 2018}

Following the inauguration of Donald Trump, the Women's March marked one of the largest protests in American history over the election of a president who openly favored antiabortion legislation and touted indifference toward police brutality against Black people. Although the march drew upon a diverse coalition of supporters (Fisher, Dow, and Ray 2017), many have argued that the concerns of middle-class White women were elevated above the needs of immigrant women and women of color (Brewer and Dundes 2018; White 2018). After all, 53 percent of White women voters selected Trump in 2016 (Rogers 2016). These tensions became more visible throughout Trump's presidency. By the 2020 election year, headline news was dominated by stories such as Amy Cooper's deliberate lie to police, evoking a trope of a Black man attacking a White woman, and the rise of the "Karen" meme as a label for White women who weaponize their racial privilege.

If the start of Trump's presidency was marked by the Women's March, the end was foreshadowed by Black Lives Matter protests against systemic racism and police violence. Despite the COVID-19 pandemic, the Black Lives Matter protests in the summer of 2020 have been reported as the largest demonstration in United States' history (Buchanan, Bui, and Patel 2020), suggesting a substantial shift in the proportion of Americans who consider racism and discrimination a social problem. Still, later that year, the majority of White women (55 percent) and men (61 percent) again voted for Trump in his failed re-election - a pattern underscoring persistent tension between the interests of diverse groups in the U.S. that will likely shape political outcomes for years to come (Blow 2020). 
Scholars of intersectionality have repeatedly shown how individuals' position within intersecting systems of race, gender, and class shapes their interests in resisting or supporting these structures of power and the ideologies that sustain them (Collins 2008; Jacobs 1987 [1861]; King 1988; Robinson 2018; Wells-Barnett 2018 [1895]). Studying the second wave of feminist activism in the 1960s and 1970s, for example, intersectionality scholars have highlighted how this movement failed to expand its political agenda across matters of race and class (Davis 1983; King 1988). The events of the past four years suggest that these tensions remain, as the interests of White women diverge from women of color, not only in patterns of political support, but also in the internal dynamics of the Women's March.

Although the Women's March and second wave feminism shared some common discord, research on public opinion indicates that contemporary views toward race and gender have changed dramatically over the four decades that separates these movements. Since the 1970s, racial attitudes have shifted from traditional forms of racism based on beliefs in inherent biological difference to new forms of racism rooted in ideologies that emphasize cultural difference and a denial of race-based discrimination (Bonilla-Silva 2014; Forman 2004; McConahay 1986; Moberg, Krysan, and Christianson 2019). These shifts are most pronounced among Whites, whereas Black racial attitudes have more consistently endorsed structuralist perspectives that emphasize the role of discrimination (Dawson 2001; Hunt 2007). With regards to gender, conventional attitudes rooted in adherence to models of women's domesticity and men's career advancement have given way to more ambivalent views, where gender equality is supported in work, but less so within the family (Cotter, Hermsen, and Vanneman 2011; Knight and Brinton 2017; Pepin and Cotter 2018). Egalitarian perspectives on gender espousing broad 
support for equality have also grown in recent years, particularly among women (Scarborough, Sin, and Risman 2019).

Intersectional theory has detailed many ways that systems of race and gender are interrelated and mutually reinforcing (Cho, Crenshaw, and McCall 2013; Collins 2008; Ferguson 2003; Hamilton et al. 2019; King 1988), but these frameworks and methods have yet to be readily applied to the study of social attitudes (see Harnois 2013 for discussion). Almost universally, survey research on attitudes impose methodological and theoretical perspectives that analytically focus on either race or gender attitudes, rather than their intersection (Chavez and Wingfield 2018; Ridgeway and Kricheli Katz 2013). Such simultaneity has gone overlooked, even though it is often the case that each research stream relies on the same datasets. The General Social Survey, for example, is commonly used for studies on racial attitudes (Carter, Mamadi, and Okerie 2018; Hunt 2007; Moberg et al. 2019) and gender attitudes (Bolzendahl and Myers 2004; Cotter et al. 2011; Scarborough et al. 2019).

In this study, we use the pooled General Social Survey (GSS) data from 1977 through 2018 to examine how changing racial attitudes co-exist with shifting gender attitudes. We use latent class analysis to account for the simultaneity of respondents possessing attitudes toward both race and gender. In doing so, we illustrate how longitudinal survey data, even when not intentionally designed to capture intersectional dynamics, may still provide useful information on the interrelationships of ideologies around gender and race. This approach allows us to answer new questions about the divergence and convergence of trends in racial and gender attitudes. Does racism preclude gender egalitarianism? Can individuals possess ideals of gender equality while continuing to deny racial disparities? How have configurations of racial and gender 
attitudes changed over time, and what does this tell us about contemporary cultural meanings behind (anti) racism and (anti) sexism?

Our results reveal a dynamic relationship between ideologies of race and gender. We uncovered four configurations of racial and gender attitudes. One perspective held views that African Americans had less motivation and will-power than Whites (referred to as new racialism) while also endorsing traditional man earner/woman caregiver gender dynamics. Another configuration to emerge integrated new racialist views with gender egalitarian beliefs that women and men should be treated equally. A third group of respondents credited the role of structural discrimination in racial inequality, alongside conventional views of gender in the family. A remaining attitudinal configuration was universally supportive of equality, attributing racial inequality to structural conditions like discrimination and holding equal expectations toward work and family for women and men.

Examining change from 1977 through 2018, we find that the relationship between new racialism and gender egalitarianism has strengthened over time, with an increasing number of individuals becoming more gender egalitarian while denying that structural factors contribute to racial inequality. A greater share of racial structuralists also now embrace gender egalitarian views, as the proportion of racial structuralists with conventional gender attitudes toward the family declined. Although growth in racial structuralist/gender egalitarian attitudes has been unstable, by 2016 this was the most common attitudinal configuration.

Comparing latent class membership across respondent characteristics, we also show that configurations of racial/gender attitudes are highly shaped by race group-interest. White men and White women are most likely to hold new racialist/gender egalitarian views, whereas Black men and Black women most commonly possess racial structuralist/gender egalitarian attitudes. We 
argue that these patterns reflect differences in the ideological functions of race and gender as social structures. White men's support for gender equality alongside new racialist views denotes that their gender egalitarianism extends only to White women, potentially because it is in their own interest to garner resources through intimate relationships. Racial group solidarity in shared attitudes among Black men and women, on the other hand, may reflect a necessary coalition to challenge racial inequality, facilitated by the intimacy of gender relations as well as spatial segregation from Whites.

\section{PARALLELS BETWEEN RACIAL AND GENDER ATTITUDES}

Despite limited overlap between studies of racial and gender attitudes, there are some parallels between these two research agendas. Broadly, each can be summarized with three types of general attitudes, the intersections of which constitute nine possible configurations of racial and gender attitudes. Table 1 illustrates these intersections.

Table 1. Hypothesized Intersection of Racial and Gender Attitudes

\begin{tabular}{c|c|c|c|}
\hline \multicolumn{1}{c}{$\begin{array}{c}\text { Traditional } \\
\text { Racialism }\end{array} \begin{array}{c}\text { Gender } \\
\text { Traditionalism }\end{array}$} & $\begin{array}{c}\text { Traditional Racialism, } \\
\text { Gender Traditionalism }\end{array}$ & $\begin{array}{c}\text { New } \\
\text { Rew Racialism } \\
\text { Gender Traditionalism }\end{array}$ & $\begin{array}{c}\text { Racial } \\
\text { Structuralism }\end{array}$ \\
\cline { 2 - 4 } $\begin{array}{c}\text { Gender } \\
\text { Ambivalent }\end{array}$ & $\begin{array}{c}\text { Traditional Racialism, Structuralism, } \\
\text { Gender Ambivalent }\end{array}$ & $\begin{array}{c}\text { New Racialism, } \\
\text { Gender Ambivalent }\end{array}$ & $\begin{array}{c}\text { Racial Structuralism, } \\
\text { Gender Ambivalent }\end{array}$ \\
\cline { 2 - 4 } $\begin{array}{c}\text { Gender } \\
\text { Egalitarianism }\end{array}$ & $\begin{array}{c}\text { Traditional Racialism, } \\
\text { Gender Egalitarianism }\end{array}$ & $\begin{array}{c}\text { New Racialism, } \\
\text { Gender Egalitarianism }\end{array}$ & $\begin{array}{c}\text { Racial Structuralism, } \\
\text { Gender Egalitarianism }\end{array}$ \\
\hline
\end{tabular}

Both racial and gender attitudes had traditional forms which existed prior to the period of Civil Rights and feminist activism in the 1960s and 1970s. Traditional racial attitudes, also 
referred to as "old-fashioned racism," were common among Whites and are characterized by the belief that racial differences are innate, rooted in biology, or "God given" (Hughes 1997;

Schuman et al. 1998). Individuals holding traditional attitudes believe racial disparities in employment, income, and health are due to inborn differences in intelligence and ability rather than individual choice, culture, or the structure of opportunity (Hunt 2007; Virtanen and Huddy 1998). Mirroring the rigid beliefs of traditional racial attitudes, those holding conventional gender attitudes believe that women are less fit for career advancement than men (Shu and Meagher 2018). This perspective combines a strong belief that the ideal family is one where the husband works and the wife tends to family and home paired with a conviction that men should be primary decision makers (Knight and Brinton 2017; Scarborough et al. 2019).

Beginning in the 1980s, there emerged new forms of both racial and gender attitudes. Multiple frameworks describe the different types of racial attitudes observed in the post-CivilRights era that predominated among Whites, including modern racism (McConahay 1986), symbolic racism (Sears et al. 1997), colorblind racism (Bonilla-Silva 2014), white racial frames (Feagin 2009), subtle prejudice (Pettigrew and Meertens 1995), racial resentment (Kinder and Sanders 1996), and laissez-faire racism (Bobo, Kluegel, and Smith 1997). Differing in emphasis, these frameworks describe a perspective that views racial disparities as the result of individuallevel behaviors, cultural deficiencies, or motivations (Bonilla-Silva 2014; Krysan 2000). Collectively, scholars have referred to these types of racial attitudes as new racism (Krysan 2000; Wilson 2006). Among Whites, new racism has largely replaced traditional attitudes regarded as socially undesirable (Krysan 1998; McConahay 1986). ${ }^{1}$

The framework of new racism has emerged primarily from research on Whites' racial attitudes. Studies of Black racial attitudes, in contrast, have found that the majority have 
historically espoused structuralist perspectives (discussed below) that attribute inequality to discrimination (Dawson 2001). However, research over the past two decades indicates that a growing number of African Americans are combining structuralist views with opinions that racial inequality also stems from cultural deficiencies or individual behaviors (Cohen 2010; Hunt 2007; Smith 2014). This sentiment shares some similarities with the expressions of new racism among Whites, but differs in that it does not necessarily negate a belief in structural explanations. Although Whites and African Americans sometimes report similar culturalist and individualist perspectives on race, these views may be rooted in fundamentally different interpretations around how these components relate to inequality and the necessary means to address it. Therefore, we use the term new racialism ${ }^{2}$ (instead of new racism) to describe similar culturalist and individualist orientations while also accounting for the possibility that these perspectives may have varying implications across race that may not be consistently labelled as racism or racist. In a similar vein, we replace the conventional usage of traditional racism with traditional racialism to accommodate our application of these configurations across race groups.

At the same time that new forms of racial attitudes emerged in the 1980s, conventional gender attitudes transitioned to more complex formations, consisting of support for gender equality in some respects, while opposing it in other situations (Cotter et al. 2011; Knight and Brinton 2017; Scarborough et al. 2019). Common among these contradictory views is support for women's professional advancement paired with the belief that women should be primarily responsible for childcare and housework (Dernberger and Pepin 2020; Grunow, Begall, and Buchler 2018; Pepin and Cotter 2018). Following previous research, we refer to this general set of contradictory views as ambivalence (Scarborough et al. 2019). ${ }^{3}$ 
A third configuration of attitudes describes progressive views on both race (structuralists) and gender (egalitarians). Racial structuralist perspectives attribute disparities between Blacks and Whites to structural features, such as discrimination and differential access to resources (Carter et al. 2018). These attitudes have historically been most common among African Americans and most closely emulate anti-racist or racially progressive perspectives through their emphasis on aspects of society that need changing, as opposed to focusing on the characteristics of individuals (Moberg et al. 2019). Mirroring these views, gender egalitarians believe women should have the same opportunities as men in the labor force and that women and men should contribute equally to housework and childcare (Knight and Brinton 2017; Grunow et al. 2018).

The parallel configurations of racial and gender attitudes resonate with theoretical work on intersectionality that has outlined multiple ways that race and gender are co-constitutive and interrelated (Collins 2008; Hamilton et al. 2019; Ken and Helmuth 2021). Scholars have observed, for example, how covertly racialized White gender norms are often deployed to construct African Americans, Latinxs, and Asians as culturally deviant (Ferguson 2003; Garcia 2012; Hamilton et al. 2019). More directly related to the study of attitudes, gender norms are often oriented toward "White just right" hegemonic standards that stereotype African Americans as overly masculinized and Asians as overly feminized (Chavez and Wingfield 2018; Ridgeway and Kricheli-Katz 2013). From this perspective, racial and gender attitudes reinforce one another. The shaded cells on the diagonal of Table 1 represent the configurations we would expect if racial and gender attitudes are correlated in such a way that traditionalists and progressives hold similar views on race and gender, and those with contemporary forms of racial and gender attitudes (new racialists and ambivalents) hold consistent perspectives toward both race and gender. 


\section{DIVERGENCE IN RACIAL AND GENDER ATTITUDES}

There are also important differences between the development of research on racial and gender attitudes. First, scholars have argued that new forms of racial attitudes are only a more subtle and covert manifestation of traditional beliefs and not a step toward anti-racist views (Bobo 1988; Forman and Lewis 2006). This is supported by research showing that individuals, particularly Whites, holding new racialist attitudes espouse equal to or greater opposition to racial policies like affirmative action than those with traditional racialist views (Hughes 1997; Tuch and Hughes 2011). In contrast, some have argued that more recent gender ambivalent attitudes are a step forward from gender traditionalism (Scarborough et al. 2019). These scholars contend that support for some aspects of gender equality is better than none.

Second, although race and gender are interrelated and mutually constitutive, they also differ in specific ways as social structures (Bonilla-Silva 1997; Risman 2018). For example, racial residential segregation imposes physical separation between race groups that contrasts starkly to the intimate proximity of women and men in different-gender relationships (BonillaSilva 1997; Jackman 1994). Correspondingly, in-group favoritism and out-group biases play a prominent role in racism (Bobo 1998), while being less central to the study of gender attitudes. Contrasting the mechanisms sustaining systems of racial and gender inequality, Jackman (1994) contends that race relations are heavily characterized by pervasive spatial segregation that facilitates aggregate exploitation, whereas gender relations are more deeply patterned by role segregation conveying different expectations for behavior in intimate settings, such as the family. These different forms of intergroup relations influence the means by which dominant groups (e.g. White men) sustain power under the guise of benevolent paternalism. Spatial segregation enables policy implementation that limits opportunities for African Americans to those that are 
expropriative. Intimate role differentiation between women and men, particularly when accompanied by mutual affection, leads to consensual support for conventional family arrangements rooted in beliefs of gendered complementarity and based on women's deference to men's interests.

Third, while many gender scholars are optimistic about signs of increasingly gender egalitarian attitudes (Meagher and Shu 2019; Scarborough et al. 2019), these expectations of continued progressive trends are less visible in research on racial attitudes, where structuralist perspectives have yet to significantly replace new racialist views among Whites (Carter et al. 2018; Moberg et al. 2019).

These divergent trends in the study of racial and gender attitudes correspond with research on policy opinions that show individuals often hold contradictory views or adopt conflicting justifications for their perspectives. In studying support for social welfare, scholars have found that individuals frequently endorse social equality while also rejecting policies intended to achieve these ends (Hochschild 2006). Value conflict is common as people increasingly embrace the ethos of individualism that justifies the curtailment of social services alongside humanitarian sympathy for those disadvantaged from circumstances beyond their control (Feldman and Zaller 1992). In resolving ideological conflicts, stated positions often end up being those that serve individuals' self-interest or convey them favorably in public settings (Kluegel and Smith 1986). When applied to racial attitudes, scholars have observed this phenomenon when Whites combine both individualist and structuralist modes of explanation for racial inequality in the U.S. These contradictory views translate to lower support for racial policy compared with individuals holding purely structuralist beliefs who reject individualist accounts (Apostle et al. 1983). 
Both the different trajectories in research on racial and gender attitudes, as well as the identification of contradictory viewpoints in the study of policy opinions, underscores the possibility that intersections of racial and gender attitudes may fall off the shaded diagonal in Table 1. In-group favoritism and out-group biases, for example, may play into Whites' possession of gender egalitarian or ambivalent views while also espousing traditional or new racialist attitudes. Conversely, racial structuralism among Black men may not translate to support for gender egalitarianism if these individuals prefer to be primary decision makers in home and work, as observed by some Black women in the Civil Rights movement (Barnett 1993; King 1988).

\section{CURRENT STUDY}

Our study is guided by the nine possible intersections of racial and gender attitudes illustrated in Table 1. We use latent class analysis on a set of eight established survey items used extensively in the study of racial and gender attitudes. This approach allows us to identify which of these nine possibilities emerge as prominent intersections describing individuals' simultaneous views toward race and gender.

In many ways, quantitative research that predominates in the study of public opinion does not lend itself to intersectional analysis examining configurations of racial and gender attitudes (Bowleg 2008; Nash 2008). The imposition of analytically independent categories such as race and gender obscure the interdependence of these social constructs and their simultaneity in individuals' lives (Sweet 2018). As a result, some scholars have argued that the positivist quantitative application of a priori social categories is antithetical to the complexities of intersectionality (Bowleg 2008). These critiques are realized most strongly in survey research, where the assumption of categorical independence is built into both the front end of survey 
design and the back end of data analysis. In survey design, the wording of racial attitude questions does not differentiate between views directed toward women or men of a certain race, while gender attitude items similarly presume consistency across race. In data analyses, the presumptions of categorical independence continue, as researchers almost uniformly examine either racial attitudes or gender attitudes, rather than their intersecting configurations.

In this study, we do not address the first issue pertaining to survey design, as this requires changing survey questions, an impossibility with our reliance on longitudinal data. We do, however, address the second critique of survey analysis that has tended to adopt a single-axis framework to study either race or gender attitudes. These approaches have often used variablecentered methods, such as alpha reliability or confirmatory factor analysis, to construct independent measures of racial and gender attitudes based on correlations between observed variables (Bolzendahl and Myers 2004; Roos, Hughes, and Reichelmann 2019). In these methods, relationships between variables are theorized by researchers and then tested to determine whether they constitute reliable constructs. While useful in generating reliable measures of latent concepts like attitudes, they ultimately reinforce the same single-axis assumption that went into the design of survey questions when the applied theoretical constructs presume (explicitly or not) that race and gender are independent and non-intersecting. This method emulates the problems with "top-down" approaches to social relations discussed by Crenshaw (1989) who argued that starting with the assumption that patterns exist within predetermined categories can obscure important details and intersections that occur in the margins of these groups. Instead, Crenshaw advocates for a "bottom-up" approach that starts with individuals and their complexities and seeks their common ground with similar others. Beginning with persons and building coalitional groups mitigates against missing important 
complexity that occurs when predetermined analytical concepts like race or gender intersect in vital ways. Our use of latent class analysis models this "bottom-up" approach by avoiding $a$ priori theoretical classifications and, instead, allowing configurations of racial/gender attitudes to emerge empirically.

In addition to examining dominant configurations, we also explore how the prevalence of these attitudes changed from 1977 through 2018 as well as their variation across respondent characteristics. Exploring longitudinal trends, we are interested in how our understanding of shifting racial and gender attitudes changes when we consider their intersections. By focusing on the relationship of attitudinal configurations to individual characteristics, we add insight on how common predictors of social attitudes, such as respondents' race/gender, birth cohort, education, social class, and religiosity, relate to more detailed formations of intersecting racial and gender attitudes. In particular, comparing views across respondents' race/gender provides insight on how individuals' location in systems of racial and gender hierarchies correspond to their attitudes.

We proceed with a series of guiding research questions that allow us to remain open to all possible attitudinal configurations illustrated in Table 1, investigate their change over time, and their relationship with respondent socio-demographic characteristics.

1) What are the predominant configurations of intersecting racial and gender attitudes?

2) How have configurations of racial/gender attitudes changed from 1977 through 2018 ?

3) How do respondents' characteristics, such as race/gender, birth cohort, education, social class, and religiosity, relate to their simultaneous racial and gender attitudes? 


\section{METHODS}

Data

We analyzed data from the General Social Survey (GSS) from 1977 through 2018 (Smith et al. 2019). The GSS is a repeated cross-sectional survey drawing nationally representative samples of people aged 18 and over who live in non-institutionalized settings within the U.S. The GSS is one of the most common datasets used in the study of racial and gender attitudes (e.g. Carter et al. 2018; Cotter et al. 2011; Hunt 2007; Moberg et al. 2019; Scarborough et al. 2019; Shu and Meagher 2018). We include 21 survey years between 1977 and 2018 in which our focal attitudinal variables are found. Our analysis includes 23,357 respondents who were nonmissing on attitudinal indicators and demographic variables used to predict attitudinal configurations.

We use eight survey items from the GSS that have each been commonly used to measure different aspects of racial and gender attitudes (Carter et al. 2018; Cotter et al. 2011; Hunt 2007; Moberg et al. 2019; Scarborough et al. 2019). Details on each item are reported in Table 2. The racial attitude items each ask respondents to report agreement with explanations for why African Americans have, on average, worse jobs, income, and housing compared with Whites. RACDIF2 measures beliefs in in-born racial differences between Blacks and Whites, an indicator of traditional racialism. RACDIF4 focuses on individual-level cultural deficiencies among African Americans, an indicator of new racialism. Two items, RACDIF1 and RACDIF3 identify respondents' awareness of the structural conditions creating challenges for African Americans in U.S. society, a measure of racial structuralism. Our interpretation of each racial attitude item corresponds to its theoretical usage in prior studies (Carter et al. 2018; Hunt 2007; Krysan 2000; Moberg et al. 2019; Wilson 2006). ${ }^{4}$ 
Table 2. GSS Racial and Gender Attitude Variables

\begin{tabular}{|c|c|c|}
\hline \multicolumn{3}{|c|}{ Racial Attitude Items } \\
\hline Survey Item & Question Wording & Response \\
\hline \multicolumn{3}{|c|}{$\begin{array}{l}\text { On the average African-Americans have worse jobs, income, and housing than } \\
\text { white people. Do you think these differences are... }\end{array}$} \\
\hline RACDIF1 & Mainly due to discrimination? & Yes, No \\
\hline RACDIF2 & $\begin{array}{l}\text { Because most African-Americans have less in-born ability } \\
\text { to learn? }\end{array}$ & Yes, No \\
\hline RACDIF3 & $\begin{array}{l}\text { Because most African-Americans don't have the chance for } \\
\text { education that it takes to rise out of poverty? }\end{array}$ & Yes, No \\
\hline RACDIF4 & $\begin{array}{l}\text { Because most African-Americans just don't have the } \\
\text { motivation or will power to pull themselves up out of } \\
\text { poverty? }\end{array}$ & Yes, No \\
\hline \multicolumn{3}{|c|}{ Gender Attitude Items } \\
\hline Survey Item & Question Wording & Response \\
\hline & Tell me if you agree or disagree with this statement: & \\
\hline FEPOL & $\begin{array}{l}\text { Most men are better suited emotionally for politics than are } \\
\text { most women }\end{array}$ & Agree, Disagree \\
\hline FEFAM & $\begin{array}{l}\text { It is much better for everyone involved if the man is the } \\
\text { achiever outside the home and the woman takes care of } \\
\text { the home and family. }\end{array}$ & Agree, Disagree \\
\hline FECHLD & $\begin{array}{l}\text { A working mother can establish just as warm and secure a } \\
\text { relationship with her children as a mother who does not } \\
\text { work. }\end{array}$ & Agree, Disagree \\
\hline FEPRESCH & $\begin{array}{l}\text { A preschool child is likely to suffer if his or her mother } \\
\text { works. }\end{array}$ & Agree, Disagree \\
\hline
\end{tabular}

We use four survey items measuring gender attitudes that have been used extensively in existing research (Bolzendahl and Myers 2004; Cotter et al. 2011; Meagher and Shu 2019; Scarborough et al. 2019). FEPOL captures respondents' beliefs about women in leadership, but has been used as an indicator of attitudes toward women in the public sphere more generally (Bolzendahl and Myers 2004; Scarborough et al. 2019). FEFAM measures respondents' adherence to conventional family structures of men's earning and women's caretaking 
responsibilities. FECHLD and FEPRESCH each capture respondents' support for working mothers. In general, conventional gender attitudes have been identified through agreement with FEPOL, FEFAM, and FEPRESCH and disagreement with FECHLD, while egalitarian views are the converse. Ambivalent gender attitudes are characterized by divergence between FEPOL, as a measure of gender attitudes toward the public sphere, and the three remaining items that relate to the private sphere of the family (Cotter et al. 2011; Scarborough et al. 2019).

\section{Latent Class Analysis: Applying Intersectional Principles to Survey Data}

Applying the principles of bottom-up theorizing to survey data, we use latent class analysis (LCA) as a person-centered methodology that starts with characteristics of individuals, such as response patterns to survey items, and identifies classes that share similar features (McLachlan and Peel 2004). Unlike variable-centered approaches, LCA does not assume latent constructs such as attitudes are continuous and linear. By modelling response patterns as a function of latent classes, LCA allows for the emergence of multidimensionality where indicators may be positively correlated in some classes, while negatively correlated in others. More specifically, LCA classifies units into $k$ classes based on the probability that respondent $i$ has similar item response probabilities among observed variables $y_{i}$ as other respondents in the class, $c$.

$$
f\left(y_{i}\right)=\sum_{k=1}^{K} P(c=k) f\left(f_{i} \mid c=k\right)
$$

LCA models latent constructs as consisting of different profiles or classes. To identify the best model for describing latent profiles, Equation 1 is applied multiple times with varying numbers of classes. Then, model fit statistics are used to compare distinctions between classes 
weighed against the cost of additional parameters. Here, we report four model fit statistics, the log-likelihood, the bootstrap p-value for the $\mathrm{L}^{2}$, the Akaike Information Criterion (AIC), and the Bayesian Information Criterion (BIC). The most commonly relied-upon fit statistic is the BIC due to its ability to weigh the costs of model complexity (additional classes) against increasing accuracy of class characterization (Nylund, Asparouhov, and Muthén 2007). Conventionally, a substantial decline in the BIC from $k-1$ to $k$ classes indicates improved model fit. Following previous research, we selected the ideal model by identifying the point at which the BIC had diminished improvement, as well as through substantive interpretation of whether additional classes added theoretical insight (Bonikowski and DiMaggio 2016; Nylund et al. 2007). We ran LCA models using the eight indicators and applying one through ten classes. Survey weights ${ }^{5}$ were used in all models to adjust for sampling design. In the results section below, we report fit statistics for each LCA model up to six classes.

After identifying the best-fitting unconstrained model, we fit local dependencies to relax the assumption of conditional independence for the selected solution (Bonikowski and DiMaggio 2016; Janssen et al. 2019). In this step, covariances were specified between indicator pairs with bivariate residuals above two and until the total bivariate residual for the model was nonsignificant (Kollenburg, Mulder, and Vermunt 2016; Schreiber 2016; Vermunt and Magidson 2013). After adding local dependencies, we then re-examined fit statistics with the newly structured LCA model for one through six classes. If the newly structured model series reports a different best-fitting latent class solution than the unconstrained models, we re-fit local dependencies to the new best-fitting solution and re-examine model fit across one- through sixclass specifications until a clear solution is identified. 
We apply this method to the pooled set of repeated cross-sectional GSS data from 1977 through 2018. This approach imposes uniform latent class definitions over time, allowing us to examine how class prevalence changes as a function of shifting cultural attitudes toward race and gender. A limitation, however, is that this method assumes that the structure of latent classes remains unchanged. To test this assumption, we conducted a series of independent latent class models with one through ten classes for each year included in the data (i.e. 210 models in total, ten for each survey year with one through ten class specifications). We recorded the BIC for each model and used this to identify the best fitting solution in each survey year. The results were consistent with the model selected from the LCA on the pooled data. To determine whether latent classes are characterized similarly across survey years, we independently applied the same latent class model selected from the analysis of the pooled data to years 1977, 1986, 1996, 2006, and 2016 and examined item response probabilities for each class. This revealed that the substantive characterization of classes was consistent across these years, indicating that the assumption of class consistency in our use of the pooled GSS is not violated. We therefore report LCA results applied to the pooled data, which allows us to more directly examine how attitudinal configurations have changed over time. Detailed results of our robustness tests are reported in the online supplement. ${ }^{6}$

\section{Latent Class Membership Over Time and By Respondent Characteristics}

After identifying predominant configurations of racial/gender attitudes, we then use multinomial logistic regression to explore the relationship of these attitudinal clusters to change over time and across respondents' demographic characteristics. There are two common methods used to examine predictors of latent class membership. In the one-step approach, exogenous variables enter the latent class model directly as covariates in simultaneous estimation of latent 
classes with added predictors (see Bonikowski and DiMaggio 2016). This approach has the benefit of efficiently identifying latent class structures and respondent class membership conditional on covariates. It is not ideal for our purposes, however, because we are interested in separately analyzing predictors of class membership from the formation of latent classes themselves. For these aims, we use a three-step approach with modifications to adjust for uncertainty in the assignment of respondents to latent classes (Bakk, Tekle, and Vermunt 2013; Vermunt 2010). The first step in this method is identifying the latent class solution. This was described above. In the second step, respondents are assigned to latent classes. We use the proportional assignment method which treats respondents as belonging to each class weighted by posterior probabilities of membership. This method is recommended in the three-step procedure used here (Vermunt and Magidson 2013) and provides more accurate estimates than other approaches, such as modal assignment (Bakk et al. 2013). ${ }^{7}$ Because respondents often have nonzero posterior membership probabilities in more than one class, corrections for classification error are necessary when predicting class membership. Therefore, in the third step we apply the maximum likelihood (ML) based correction method (Vermunt 2010) that incorporates estimates of latent class membership probabilities into a multinomial logistic regression model. This allows us to examine predictors of class membership while accounting for uncertainty in the probabilistic classification of respondents to classes.

In this third step, we use a single multinomial logistic regression equation to estimate predicted probabilities of class membership across survey years and respondent characteristics. As with the latent class models, we use survey weights in this step of our analysis. In reporting results, we focus on three main groups of predictors. First, we report predicted probabilities of class membership by survey year to examine changing attitudinal configurations over time. Then 
we focus on differences in latent class membership by respondent race and gender, as these constitute the social categories that configurations of racial/gender attitudes are directed toward. Because the GSS did not identify Latinx or Asian respondents prior to the late 1990s, we focus primarily on differences between White men, White women, Black men, and Black women as they are consistently identified throughout all years of our study. Our use of these race/gender groups provisionally imposes binary gender categories which conflate sex and gender because the GSS did not differentiate between sex at birth and gender identity until 2018 (Lagos and Compton 2021). ${ }^{8}$ Finally, we examine predicted probabilities of class membership by respondent characteristics found in previous research to have a strong relationship to racial or gender attitudes. Providing insight on cohort effects, we explore generational differences between PreBaby Boomers (born prior to 1946), Baby Boomers (1946 through 1964), Generation-Xers (1965 through 1980), and Millennials and Gen-Z respondents (born after 1980). ${ }^{9}$ We also report differences by education (college or more, some college, high school degree or equivalent, and less than high school), and region (Northeast, Midwest, South, and West) because both gender and racial attitudes have been found to vary across these components (Hunt 2007; Scarborough and $\operatorname{Sin} 2020) .{ }^{10}$ We next report the relationship of social class and religiosity to attitudinal configurations as these two characteristics have been shown to shape individuals' cultural orientations (Bobo and Kluegel 1993; Schnabel 2016). Although social class is sometimes indirectly measured through education, we chose two additional indicators to capture this characteristic. First, we examine differences by broad occupation (managerial/professional, service, sales/office, natural resource extraction/construction, production/transportation, and not employed), which have been found to be constitutive of social class. ${ }^{11}$ Second, we examine respondents' subjective social class identification as upper, middle, working, or lower class. Two 
additional items measure religiosity. The first identifies respondents' religion as traditional, moderate, or liberal. ${ }^{12}$ The second measures the frequency of attendance at religious services (every week, monthly, a few times a year, or less than once a year).

Our results are presented in three sections. First, we report model fit statistics from the LCA that we use to identify the ideal latent class structure for describing configurations of racial/gender attitudes. Next, we report item response probabilities of indicators to characterize latent classes. In the third section, we turn to the results of the multinomial logistic regression model predicting class membership. We devote special attention to predicted probabilities of class membership across survey years to infer attitudinal shifts over time. Then, we focus on differences between White men, White women, Black men, and Black women to draw insight on the relationship between respondents' intersecting social location across race and gender and their configuration of racial/gender attitudes. Lastly, we report differences in latent class membership by additional respondent socio-demographic characteristics as calculated by our multinomial logistic regression model.

\section{RESULTS}

\section{LCA Model Fit}

Table 3 reports fit statistics for LCA models with one through six classes. Model fit for the unconstrained models (Panel A) improves across all indicators from one through six classes, although there are diminishing returns. In particular, there is limited improvement in model fit across the log-likelihood, BIC, and AIC when moving from the five- to the six-class model. For instance, the BIC reduces by only .15 percent when adding a sixth class, suggesting that the sixclass model does not provide substantial gains in fitting response patterns. The $\mathrm{p}$-value for the $\mathrm{L}^{2}$ statistic provides little information because results were significant across all models. In these 
cases, scholars recommend relying on penalized log-likelihood statistics such as the BIC

(Nylund et al. 2008).

Table 3. Latent Class Model Fit Statistics

Panel A: Unconstrained Models

\begin{tabular}{|c|c|c|c|c|c|c|}
\hline & 1 & 2 & 3 & 4 & 5 & 6 \\
\hline Log-likelihood & -116583.82 & -109416.48 & -107379.63 & -106751.79 & -106191.99 & -105989.35 \\
\hline Bootstrap $L^{2} p$-value & 0.000 & 0.000 & 0.000 & 0.000 & 0.000 & 0.000 \\
\hline BIC & 233248.16 & 219004.07 & 215020.93 & 213855.83 & 212826.81 & 212512.12 \\
\hline AIC & 233183.64 & 218866.97 & 214811.25 & 213573.57 & 212471.97 & 212084.70 \\
\hline$N$ of parameters & 8 & 17 & 26 & 35 & 44 & 53 \\
\hline$d f$ & 247 & 238 & 229 & 220 & 211 & 202 \\
\hline \multicolumn{7}{|c|}{ Panel B: Models with Local Dependencies Identified for Five-Class Solution } \\
\hline & 1 & 2 & 3 & 4 & 5 & 6 \\
\hline Log-likelihood & -112382.84 & -108007.44 & -106242.01 & -105636.24 & -105594.8034 & -105572.18 \\
\hline Bootstrap $\mathrm{L}^{2} \mathrm{p}$-value & 0.000 & 0.000 & 0.000 & 0.000 & 0.000 & 0.000 \\
\hline $\mathrm{BIC}$ & 224966.97 & 216306.74 & 212866.47 & 211745.51 & 211753.2213 & 211798.55 \\
\hline AIC & 224805.68 & 216072.87 & 212560.02 & 211366.48 & 211301.6067 & 211274.36 \\
\hline$N$ of parameters & 20 & 29 & 38 & 47 & 56 & 65 \\
\hline$d f$ & 235 & 226 & 217 & 208 & 199 & 190 \\
\hline \multicolumn{7}{|c|}{ Panel C: Models with Local Dependencies Identified for Four-Class Solution } \\
\hline & 1 & 2 & 3 & 4 & 5 & 6 \\
\hline Log-likelihood & -112781.99 & -108079.56 & -106267.73 & -105641.84 & -105618.05 & -105580.95 \\
\hline Bootstrap $L^{2} p$-value & 0.000 & 0.000 & 0.000 & 0.000 & 0.000 & 0.000 \\
\hline BIC & 225755.20 & 216440.93 & 212907.84 & 211746.65 & 211789.65 & 211806.04 \\
\hline AIC & 225601.98 & 216215.12 & 212609.45 & 211375.68 & 211346.10 & 211289.90 \\
\hline$N$ of parameters & 19 & 28 & 37 & 46 & 55 & 64 \\
\hline$d f$ & 236 & 227 & 218 & 209 & 200 & 191 \\
\hline
\end{tabular}

Note: Shaded latent class solution indicates selected model.

$\mathrm{BIC}=$ Bayesian Information Criterion; AIC $=$ Akaike Information Criterion; $\mathrm{df}=$ degrees of freedom

Based on the fit statistics for the unconstrained models, the five-class solution provides

the best initial fit. However, conditional independence is a key assumption with LCA modeling.

When we add local dependencies to relax the assumption of conditional independence in fitting

the five-class solution ${ }^{13}$ and apply this structure to models with one through six classes (Panel

B), we find that the five-class solution reports a higher BIC, and worse fit, than the four-class

solution. We therefore re-examined our latent class models by fitting local dependencies to the 
unconstrained four-class solution ${ }^{14}$ and applied this new structure to one- through six-class models (Panel C). In this series, the four-class solution again reports the lowest BIC, providing evidence that this solution is ideal for describing configurations of racial and gender attitudes.

Examining model fit across latent class specifications reveals that the four-class solution with fitted local dependencies (reported in Table 3, Panel C) provides the best fit with the fewest parameters. To determine whether this solution also offers advantages in substantive latent class characterization, we examined item response probabilities from latent class solutions with three, four, and five classes using the models from Panel C in Table 3. These results are reported in the online supplement and briefly discussed here.

We found that the three-class solution generated three similarly-sized clusters representing distinct attitudinal configurations corresponding to racial structuralism/gender egalitarianism, new racialism/gender traditionalism, and new racialism/gender egalitarianism (details characterizing these configurations are provided in the following section). The four-class solution added further detail by identifying an additional configuration of racial structuralist/gender ambivalent attitudes that contained $43 \%$ of respondents previously classified as new racialist/gender traditionals in the three-class model. The addition of a fourth class therefore captures a substantively different attitudinal configuration with respect to both racial and gender attitudes. Moving to the five-class solution, we again found the same attitudinal configurations observed in the four-class solution, as well as an additional cluster containing only 3 percent of the sample. This new group reclassified 2.6 percent of respondents previously identified in the four-class model as new racialist/gender traditionals, and 3.3 percent previously classified as racial structuralist/gender ambivalents. Respondents in the additional fifth class were more embracing of structuralist interpretations of racial inequality than new racialists, but 
not to the extent of racial structuralists. They also had slightly more conventional gender attitudes than gender ambivalents. In other words, the fifth class differed only in degree from those identified in the four-class solution and offered little substantive insight on unique configurations of $\mathrm{racial} / \mathrm{gender}$ attitudes.

The four-class solution reported the best and most parsimonious model fit after including local dependencies. It also provided the most theoretical insight on distinct response patterns. We therefore proceed in analyzing the four-class model with local dependencies to describe configurations of racial and gender attitudes.

\section{Profiles of Racial/Gender Attitudes}

To characterize each latent class, Table 4 reports item response probabilities across the eight attitudinal measures and Figure 1 visualizes these trends for affirmative outcomes on each indicator ("yes" to racial attitude items and "agree" to gender attitude items). Table 5 summarizes the results of the four-class model with the three-by-three table we used to frame our analysis. Of the nine possible combinations of racial and gender attitudes, four emerged. Almost a third (31 percent) of respondents were classified as racial structuralist/gender egalitarians. These individuals most embodied anti-racist and feminist ideals. They believed racial inequality results from discrimination and limited access to educational opportunities and rejected explanations of inequality stemming from in-born abilities or motivation. They also believed women are just as suited for politics as men, felt that women and men should take equal roles in family labor, and supported working mothers. 
Table 4. Item Response Probabilities By Class

\begin{tabular}{|c|c|c|c|c|}
\hline & 1 & 2 & 3 & 4 \\
\hline $\begin{array}{l}\text { Conditional } \\
\text { Probabilities of } \\
\text { Responses }\end{array}$ & $\begin{array}{c}\text { Racial } \\
\text { Structuralism, } \\
\text { Gender } \\
\text { Egalitarianism }\end{array}$ & $\begin{array}{c}\text { New Racialism, } \\
\text { Gender } \\
\text { Traditionalism }\end{array}$ & $\begin{array}{c}\text { Racial } \\
\text { Structuralism, } \\
\text { Gender } \\
\text { Ambivalent } \\
\end{array}$ & $\begin{array}{c}\text { New Racialism, } \\
\text { Gender } \\
\text { Egalitarianism }\end{array}$ \\
\hline Class Size & $31 \%$ & $19 \%$ & $18 \%$ & $32 \%$ \\
\hline \multicolumn{5}{|c|}{ Racial inequality due to discrimination? } \\
\hline No & 0.330 & 0.881 & 0.320 & 0.856 \\
\hline Yes & 0.670 & 0.119 & 0.680 & 0.144 \\
\hline \multicolumn{5}{|c|}{ Racial inequality because most African Americans have less in-born ability to learn? } \\
\hline No & 0.924 & 0.811 & 0.785 & 0.897 \\
\hline Yes & 0.076 & 0.189 & 0.215 & 0.103 \\
\hline
\end{tabular}

Racial inequality because most African Americans don't have the chance for education that it takes to rise out of poverty?
No
0.218
0.790
0.212
0.789
Yes
0.782
0.210
0.788
0.211

Racial inequality because most African Americans just don't have the motivation or will power to pull themselves up out of poverty?
No
0.806
0.201
0.565
0.310
Yes
0.194
0.799
0.435
0.690

Most men are better suited emotionally for politics than are most women.
Agree
0.121
0.423
0.367
0.205
Disagree
0.879
0.577
0.633
0.796

It is much better for everyone involved if the man is the achiever outside the home and the woman takes care of the home and family.
Agree
0.125
0.755
0.669
0.172
Disagree
0.875
0.245
0.331
0.828

A working mother can establish just as warm and secure a relationship with her children as a mother who does not work.
Agree
0.924
0.253
0.364
0.881
Disagree
0.076
0.747
0.636
0.119

A preschool child is likely to suffer if his or her mother works.

$\begin{array}{lllll}\text { Agree } & 0.127 & 0.904 & 0.856 & 0.135 \\ \text { Disagree } & 0.873 & 0.096 & 0.144 & 0.865\end{array}$


Table 5. Summary of LCA Results for the Intersection of Racial and Gender Attitudes

\begin{tabular}{|c|c|c|c|}
\hline & $\begin{array}{l}\text { Traditional } \\
\text { Racialism }\end{array}$ & $\begin{array}{c}\text { New } \\
\text { Racialism } \\
\end{array}$ & $\begin{array}{c}\text { Racial } \\
\text { Structuralism } \\
\end{array}$ \\
\hline $\begin{array}{c}\text { Gender } \\
\text { Traditionalism }\end{array}$ & $\begin{array}{l}\text { Traditional Racialism, } \\
\text { Gender Traditionalism }\end{array}$ & $\begin{array}{c}\text { New Racialism, } \\
\text { Gender Traditionalism } \\
19 \%\end{array}$ & $\begin{array}{l}\text { Racial Structuralism, } \\
\text { Gender Traditionalism }\end{array}$ \\
\hline $\begin{array}{c}\text { Gender } \\
\text { Ambivalent }\end{array}$ & $\begin{array}{l}\text { Traditional Racialism, } \\
\text { Gender Ambivalent }\end{array}$ & $\begin{array}{l}\text { New Racialism, } \\
\text { Gender Ambivalent }\end{array}$ & $\begin{array}{c}\text { Racial Structuralism, } \\
\text { Gender Ambivalent } \\
18 \%\end{array}$ \\
\hline $\begin{array}{c}\text { Gender } \\
\text { Egalitarianism }\end{array}$ & $\begin{array}{l}\text { Traditional Racialism, } \\
\text { Gender Egalitarianism }\end{array}$ & $\begin{array}{c}\text { New Racialism, } \\
\text { Gender Egalitarianism } \\
32 \%\end{array}$ & $\begin{array}{c}\text { Racial Structuralism, } \\
\text { Gender Egalitarianism } \\
31 \%\end{array}$ \\
\hline
\end{tabular}

Figure 1. Affirmative [Yes/Agree] Item Response

Probabilities by Latent Class

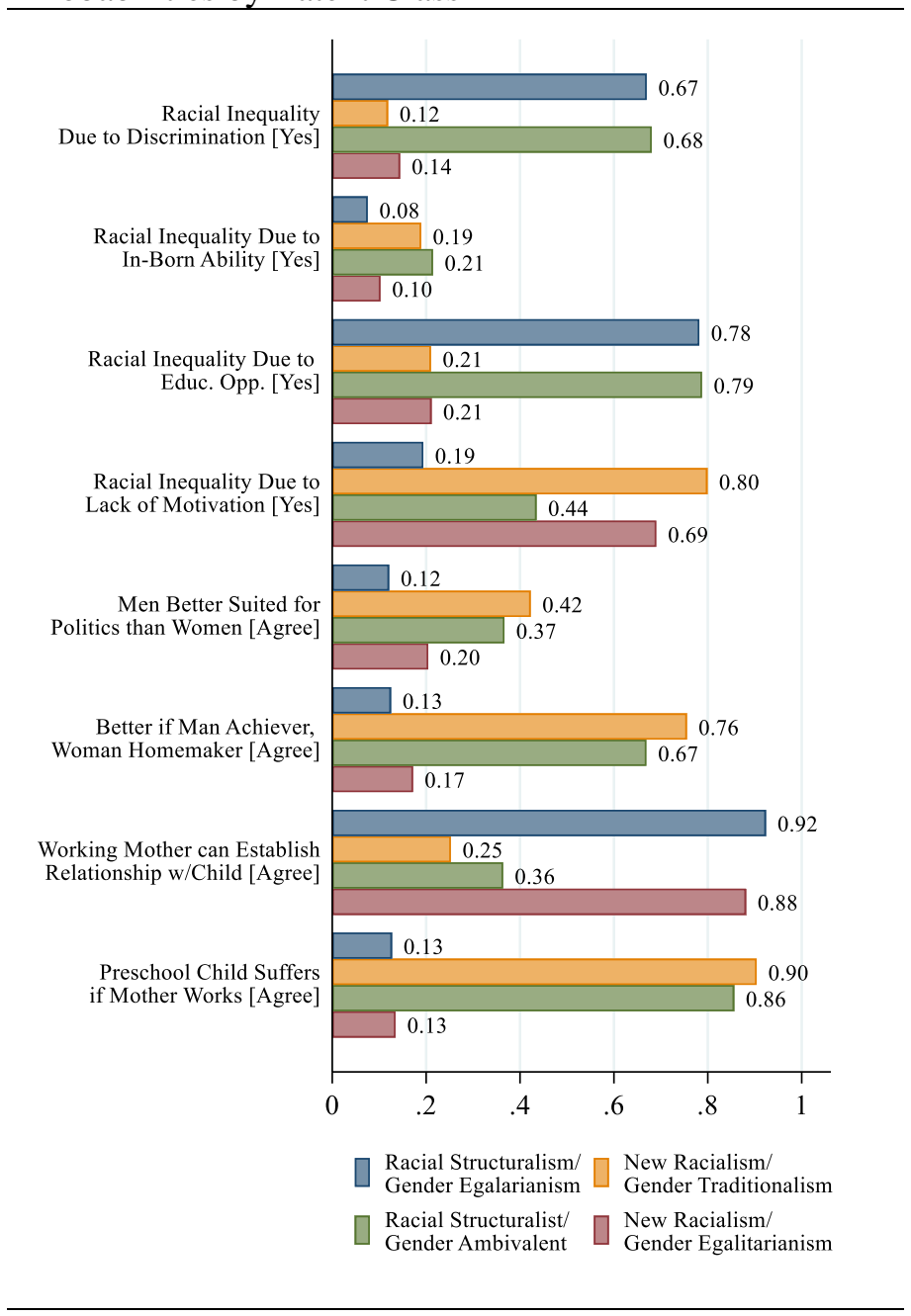


In greatest opposition to racial structuralist/gender egalitarians is the class of new racialist/gender traditionals who made up about one-fifth of the sample. These individuals were the most likely to believe racial inequality is due to a lack of motivation on the part of African Americans. Although this belief was by far the most prevalent among members of this class, it is notable that these respondents were about as likely to perceive racial inequality as resulting from racial differences in in-born ability as they were to view it as resulting from discrimination or educational inequities. New racialist/gender traditionals are also characterized by the most conventional views on gender. Across all four gender attitude indicators, new racialist/gender traditionals were more likely than all other latent classes to hold conventional beliefs. These views were strongest on the three items related to family, where respondents endorsed men's primary responsibility for financially providing for their families and opposed mothers' employment. Respondents in this class were also more likely than those in the three other classes to believe women were unsuited for politics, although the item response probabilities indicate that a slight majority reject this claim. This confirms previous research on gender attitudes showing that opposition to women's political and public sphere participation has decreased in recent decades, even among those who hold the most traditional outlooks on gender (Scarborough et al. 2019). Indeed, when conducting independent latent class models across each decade of survey data (see online supplement), the item response probabilities from 1977 and 1986 showed greater opposition than support for women in politics among these respondents, whereas in 1996, 2006, and 2016 support for women in politics became slightly more common in this cluster. Therefore, we refer to the gender attitudes of this group as embodying traditional beliefs, with the recognition that, to a large extent, "modern day traditionals" are slightly less opposed to women in politics. 
The third latent class to emerge consisted of 18 percent of respondents and is labelled racial structuralism/gender ambivalent. These respondents believe that racial inequality is due to discrimination and disparate access to educational opportunities. The item response probabilities indicate that endorsement of these structuralist explanations for inequality is similar to those found among the racial structuralist/gender egalitarian class. Of note, however, racial structuralist/gender ambivalent respondents were more likely than their gender egalitarian counterparts to agree that a lack of will power on the part of African Americans contributes to racial inequality. They were also similarly as likely as new racialist/gender traditionals to endorse racial differences in-born abilities. Yet, affirmative response probabilities for these items were far lower than those corresponding to structuralist explanations (see Figure 1). Furthermore, previous research has found that those espousing traditional beliefs in in-born differences often feel that discrimination and educational inequities play a role as well (Hunt 2007). By conceptualizing two clusters of racial structuralist attitudes (gender egalitarian and gender ambivalent), we find that this correlation exists primarily among those with gender ambivalent perspectives. Specifically with regard to gender attitudes, this configuration most represents ambivalent views that support gender equality in the public sphere (women suited for politics), while at the same time endorsing conventional gender arrangements domestically (opposing mothers' employment and embracing husband earner/wife caretaker family arrangements). Unlike new racialist/gender traditional attitudes, this pattern of ambivalence was more stable when analyzing independent latent class models for each survey year. The combination of racial structuralist views and ambivalent gender attitudes among this class resonates with intersectional scholarship on the Civil Rights and Black Liberation movements, which illustrated the way anti- 
racism often coexisted alongside traditional beliefs around women's role in the family (Barnett 1993; King 1988).

The last latent class contained about a third of respondents (32 percent). These individuals held new racialist/gender egalitarian views. They were more likely to feel that racial inequality resulted from a lack of motivation among African Americans than in-born ability, discrimination, or educational disparities. In terms of gender attitudes, this class was universally egalitarian, agreeing that women are just as suited for politics as men, supporting mothers' employment, and opposing conventional gender divisions of family labor. The combination of new racialism and gender egalitarian views in this class resonates with critiques of White feminism by scholars identifying how racism often occurs alongside views advocating for women's rights and gender equality (Davis 1984; hooks 1981; King 1988).

These intersections generate new theoretical insight on the relationship between racial and gender attitudes. First, our findings indicate that the most traditional gender attitudes only occur alongside regressive new racialist beliefs. Meanwhile, we did not observe strongly held traditional racialist beliefs in any latent class. This is consistent with prior research showing that the expression of biological essentialism had largely faded by the late 1970s, when it was replaced by new racialist views rooted in culturalist and individualist explanations of racial difference and inequality (McConahay 1986). Thus, new racialist views form the primary basis of regressive racial ideology in the period under study (Bonilla-Silva 2014). Our finding that traditional gender attitudes occur only among new racialists suggests that progressive structuralist views toward race are incompatible with the most regressive form of traditional gender attitudes combining opposition to women in political leadership with ongoing support for conventional arrangements in the family. 
Second, our findings show that while racial structuralism does not occur alongside the most traditional views on gender, racial structuralists sometimes hold gender ambivalent attitudes and gender egalitarians often hold new racialist perspectives. Gender egalitarians were about equally as likely to hold views in line with new racialism as racial structuralism. These findings suggest that notions of gender egalitarianism commonly incorporate elements of new racialism. Racial structuralists, on the other hand, were almost twice as likely to hold gender egalitarian views, but a substantial share also held gender ambivalent perspectives that supported gender equality in the public sphere, but felt women should be primarily responsible for household and family labor. These two trends suggest that progressive gender and racial attitudes need not co-exist and, in fact, often diverge.

\section{Configurations of Racial/Gender Attitudes Over Time and Across Respondent Characteristics}

In this section, we report the results from the multinomial logistic regression model predicting membership in each class of racial/gender attitudes. Full results of the model are provided in the appendix, Table A1. Here, we report conditional predicted probabilities of class membership derived from those results. We begin by focusing on longitudinal change between 1977 and 2018. We then focus on differences by respondents' race/gender, before turning to additional socio-demographic predictors.

Class membership over time. Figure 2 presents trends in predicted probabilities of class membership for each survey year, calculated from the multinomial logistic regression model reported in Table A1. In broad strokes, we observe a flip in latent class membership trends such that the most prevalent attitudinal configurations in 1977 were the least common in 2018, and vice-versa. Examining the most regressive attitudinal configuration of new racialist/gender traditionals, we find that this class was more prevalent than all others in 1977 when the 
probability of membership was nearly .40. From this point through 1993, membership probabilities declined dramatically. After 1993, however, we observe an increase in the prevalence of this class until reaching a second, smaller, peak in 2000 at .25. Growing traditionalism during this time resonates with research on the stalled gender revolution showing diminished progress on multiple gender equality indicators and a slight backlash against egalitarian attitudes in the mid- to late-1990s (England, Levine, and Mishel 2020). Indeed, there is a dip in prevalence during this period for both configurations containing egalitarian gender attitudes alongside a rise in both classes with non-gender egalitarian views. After 2000 , there is a steady decline in the new racialist/gender traditionalist group. By 2018, it had a lower probability of membership than all other classes (.08).

Figure 2. Latent Class Prevalence by Year

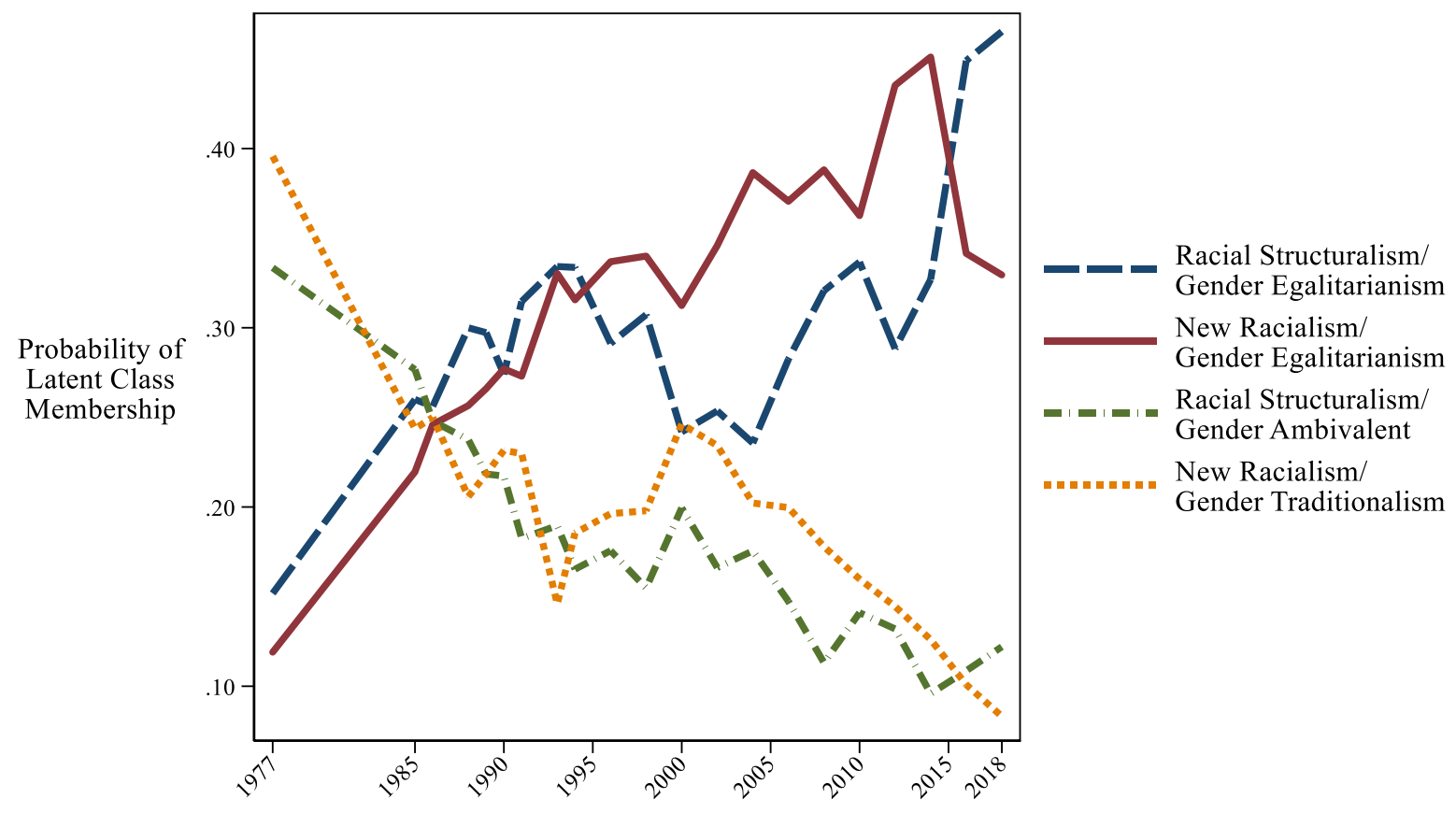

Note: Probabilities of latent class membership calculated from multinomial logistic regression model using ML-based correction method (Bakk et al. 2013; Vermunt 2010). Full results reported in Table A1. 
Tracking closely with new racialism/gender traditionalism, the racial structuralist/gender ambivalent class was the second most common in 1977 (membership probability of .33) and declined steadily until the early 1990s. At this point, membership probabilities plateaued at around .16, with a brief uptick in 2000 when the probability of membership rose to .20 . Following 2000, racial structuralist/gender ambivalent class membership probabilities declined steadily, reaching .10 in 2014. Since then, there's been a slight increase in 2016 and 2018, but this perspective remains less common.

The two classes of racial structuralism/gender egalitarianism and new racialism/gender egalitarianism both grew in prevalence at similar rates from 1977 through the early 1990s. In 1977, these classes were uncommon, with membership probabilities of only .15 and .12 , respectively. By 1993, each group had more than doubled in size, reaching a predicted membership probability of .33 . This coincided with the sharp decline in racial structuralism/gender ambivalence and new racialism/gender traditionalism taking place from 1977 to 1993 . Together, these trends reveal a general increase in gender egalitarian attitudes from the late 1970s through the early 1990s occurring among both racial structuralists and new racialists to a similar extent. This increase in gender egalitarian views during this period has been observed elsewhere (Scarborough et al. 2019), but here we show that it coincided with virtually no change in the prevalence of racial structuralist perspectives. Instead, the total probability of belonging to either racial structuralist class changed very little from $1977(.48)$ to $1993(.52)$. Meanwhile, the total predicted probability of belonging to either of the two classes with gender egalitarian views more than doubled from .27 in 1977 to .66 in 1993. Importantly, about half of the increase in gender egalitarian attitudes occurred among those who simultaneously held new racialist views. This pattern adds support to critiques of White feminism which have argued that, 
to a large extent, growing gender egalitarianism has done little to challenge racism (Davis 1984; hooks 1981; King 1988).

Turning to the period of the "stalled gender revolution" in the mid- to late-1990s, we find diminished growth in both classes with egalitarian gender attitudes, but the stall was much greater among those holding racial structuralist perspectives. From 1993 through 2000, probabilities of class membership fell by .02 for the new racialist/gender egalitarian class, while declining over four times as much (.09) for the racial structuralist/gender egalitarian class. Overall, the stall in egalitarian gender attitudes was far more pronounced when occurring alongside racial structuralist perspectives.

Following 2000, Figure 2 reports resumed growth in gender egalitarianism, but first among new racialists and later among racial structuralists. A major shift occurred from 2014, where the prevalence of new racialism/gender egalitarianism dropped rapidly while racial structuralist/gender egalitarian views became the most common. This pattern provides preliminary evidence of growing unification between progressive gender and racial attitudes. It is possible that the incorporation of intersectionality in anti-racist and feminist movements in recent history has contributed to these trends. Supporting this interpretation is the dramatic increase in racial structuralism/gender egalitarianism between 2012 (.28) and $2016(.45)$, a period of time when Black Lives Matter was founded (2013) and protests following the killing of Michael Brown in 2014 launched the movement nationwide. The discourse conveyed by Black Lives Matter has incorporated intersectional principles which advocate simultaneously for both racial and gender equality (Ransby 2018; Taylor 2016). It is likely that the recent shifts in racial/gender attitudes are related to this movement and the cultural change it both represents and contributes to. 
In summary, examining longitudinal change reveals dynamic relationships between ideologies of race and gender. ${ }^{15}$ With the exception of the most recent years, growing gender egalitarianism since the late 1970s has not occurred alongside an increase in racial structuralism. This is because much of the rise in gender egalitarian attitudes has taken place among those who continue to espouse new racialist views. Our findings add new insight to the study of gender attitudes by revealing how increasingly progressive attitudes on one dimension (gender) do not necessarily incorporate progressive views in another (race). Instead, these trends suggest that growing gender egalitarianism has been, in large part, driven by a sizable portion of the population who have not abandoned regressive new racialist views.

In contrast, we find that racial structuralism took place primarily among those who also embrace gender egalitarianism. With little deviation, the prevalence of racial structuralism/ gender ambivalence declined from 1977 through 2018. Instead, the only growth in racial structuralism during this period occurred among those also holding gender egalitarian views. Thus, while growing gender egalitarianism did not necessarily incorporate racial structuralism, we find that the increase in racial structuralist views took place primarily alongside gender egalitarian attitudes. Collectively, these patterns suggest that racial structuralism has increasingly embraced gender equity, but gender egalitarianism has not encompassed racial equity.

Class Membership by Race and Gender. Examining class membership by respondent race and gender allows us to observe how individuals' structural location within systems of race and gender correspond with attitudes. Figure 3 presents the probabilities of class membership for White men, White women, Black men, and Black women calculated from the multinomial logistic regression model reported in the appendix, Table A1. Unfortunately, the GSS did not 
identify Latinx or Asian respondents prior to the late 1990s. Therefore, we focus on Black and White respondents because they were consistently identified throughout all years of this analysis.

Figure 3. Latent Class Membership by Respondent Race and Gender

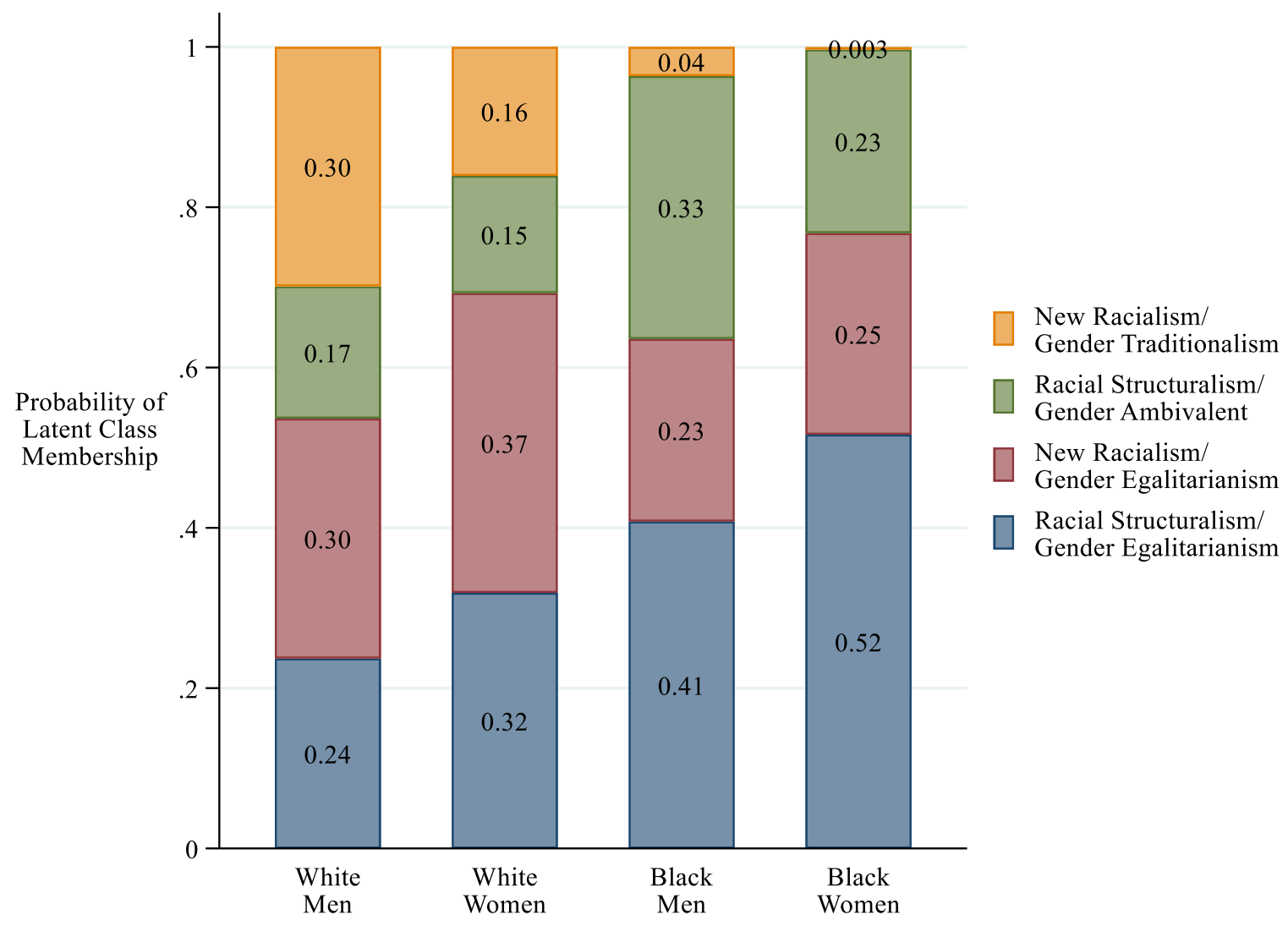

Note: Probabilities of latent class membership calculated from multinomial logistic regression model using ML-based correction method (Bakk et al. 2013; Vermunt 2010). Full results reported in Table A1. Sample sizes for each subgroup: White men 8,390, White women 10,465, Black men 1,132, and Black women 1,995.

Racial structuralism/gender egalitarianism is the most prevalent attitude for both Black men and Black women, who were more likely to belong to this cluster than any other $(\mathrm{p}<.001)$. In contrast, new racialism/gender egalitarianism is the most prevalent category for White women $(\mathrm{p}<.001)$ and one of two categories with the highest probability of membership for White men who also held similar levels of new racialism/gender traditionalism. These findings suggest that 
race group-interest plays a larger role than gender-based solidarity. White men, who theoretically benefit from regressive gender and racial ideologies, are just as likely to exhibit new racialist views alongside gender egalitarian perspectives as they are to hold new racialist views alongside gender traditional attitudes. This suggests that their support for gender equality extends primarily to White women, since the combination of new racialism and gender egalitarianism would still frame Black women as unfavorable on the basis of their race. White women with gender egalitarian views, meanwhile, were more likely to possess new racialist than racial structuralist attitudes - suggesting that many of these respondents' perspectives on gender equality were restricted to Whites. Racial group solidarity among Black respondents appeared more encompassing of social equity. It is likely that Black men with racial structuralist views recognized that racial equity for Black women also necessitated progressive gender attitudes. This is also consistent with prior research showing that Black men have historically had more gender egalitarian attitudes corresponding with Black women's longstanding participation in the labor force (Kane 2000).

Although race group-interest is evident in the class with the highest probability of membership for each subset of respondents illustrated in Figure 3, there is also evidence for a secondary effect that is more specific to race/gender group-interest. The predicted probability of membership for each latent class was largest for the subgroup who stood the most to benefit from the associated attitude. White men were more likely to hold new racialist/gender traditional views than all other groups $(\mathrm{p}<.001)$. Importantly, Figure 3 reports a sizable gap representing the extent by which White men held these regressive views: They are nearly twice as likely as White women, 7.5 times as likely as Black men, and approximately 100 times more likely than Black 
women to espouse new racialist/gender traditional perspectives. White men were also the least likely to hold racial structuralist/gender egalitarian attitudes.

In contrast, Black women had the highest probability of membership in the racial structuralist/gender egalitarian class $(\mathrm{p}<.001)$ alongside the lowest probability of class membership in the new racialist/gender traditional class $(\mathrm{p}<.05)$. The size of these effects is notable. The predicted probability of Black women's membership in the most regressive new racialist/gender traditional class is virtually zero (.003) whereas their probability of membership in the most progressive class of racial structuralism/gender egalitarianism is over .5.

Specific race/gender group-interest is also observed among White women who had the highest probability of membership in the new racialist/gender egalitarian class that challenged gender inequality while reinforcing racial inequality $(\mathrm{p}<.001)$. Mirroring these trends, Black men were more likely than others to hold racial structuralist/gender ambivalent views that espoused anti-racist attitudes while continuing to feel women should perform most of the household labor $(\mathrm{p}<.001)$

In sum, the results from Figure 3 suggest that attitudes appear to be driven foremost by race group-interest and secondarily by race/gender group-interest. The highest probability of membership for each subgroup was for the class that was in the best interest of both women and men of their race. Comparing class representation, each latent class was most represented in the race/gender subgroup under which the greatest gains would be provided. In the case of Black women and White men, we find strong evidence for the role of structural locations in shaping personal outlooks. White men privileged from systems of race and gender were more likely than all other subgroups to hold regressive opinions on both dimensions, whereas Black women 
positioned at the intersection of both racism and sexism were the most likely to possess attitudes that challenge these hierarchies of power.

\section{Class Membership by Respondent Socio-Demographic Characteristics. Our multinomial}

logistic regression model predicting latent class membership also included a number of additional covariates intended to provide a more extensive profile of respondents holding each attitudinal configuration. Model results are reported in the appendix, Table A1, and predicted probabilities of latent class membership across respondent characteristics are illustrated in Figures 4 and 5.

Across each set of respondent characteristics, we find significant differences in predicted latent class membership. The largest differences are observed between the most progressive class of racial structuralism/gender egalitarianism and the most regressive class of new racialism/gender traditionalism. Racial structuralist/gender egalitarians tend to belong to younger birth cohorts (Millennial/Gen-Z), have college degrees, reside in the West or Northeast regions, hold managerial/professional occupations, self-identify as upper/middle class, and are less religious. In direct contrast, new racialist/gender traditionals are more likely to be in an older birth cohort (Pre-Baby Boomers), have low levels of education, reside in the South, work in blue-collar occupations, and be more religious. Consistent with research showing that cohort replacement plays a large role in cultural change (Kiley and Vaisey 2020), we find that differences between birth cohorts is one of strongest predictors of latent class membership, as Pre-Baby Boomers are about four times as likely as Millennials/Gen-Zs to belong to the new racialist/gender traditionalist class, while being less than half as likely to hold racial structuralist/gender egalitarian views. Also substantiating previous research, we found educational differences to be one of the strongest predictors (Hunt 2007; Scarborough et al. 
2019). In particular, those with a college degree are over three times as likely to possess racial structuralist/gender egalitarian attitudes than those with less than a high school education.

Figure 4. Probabilities of Latent Class Membership by Respondent Birth Cohort, Education, and Region
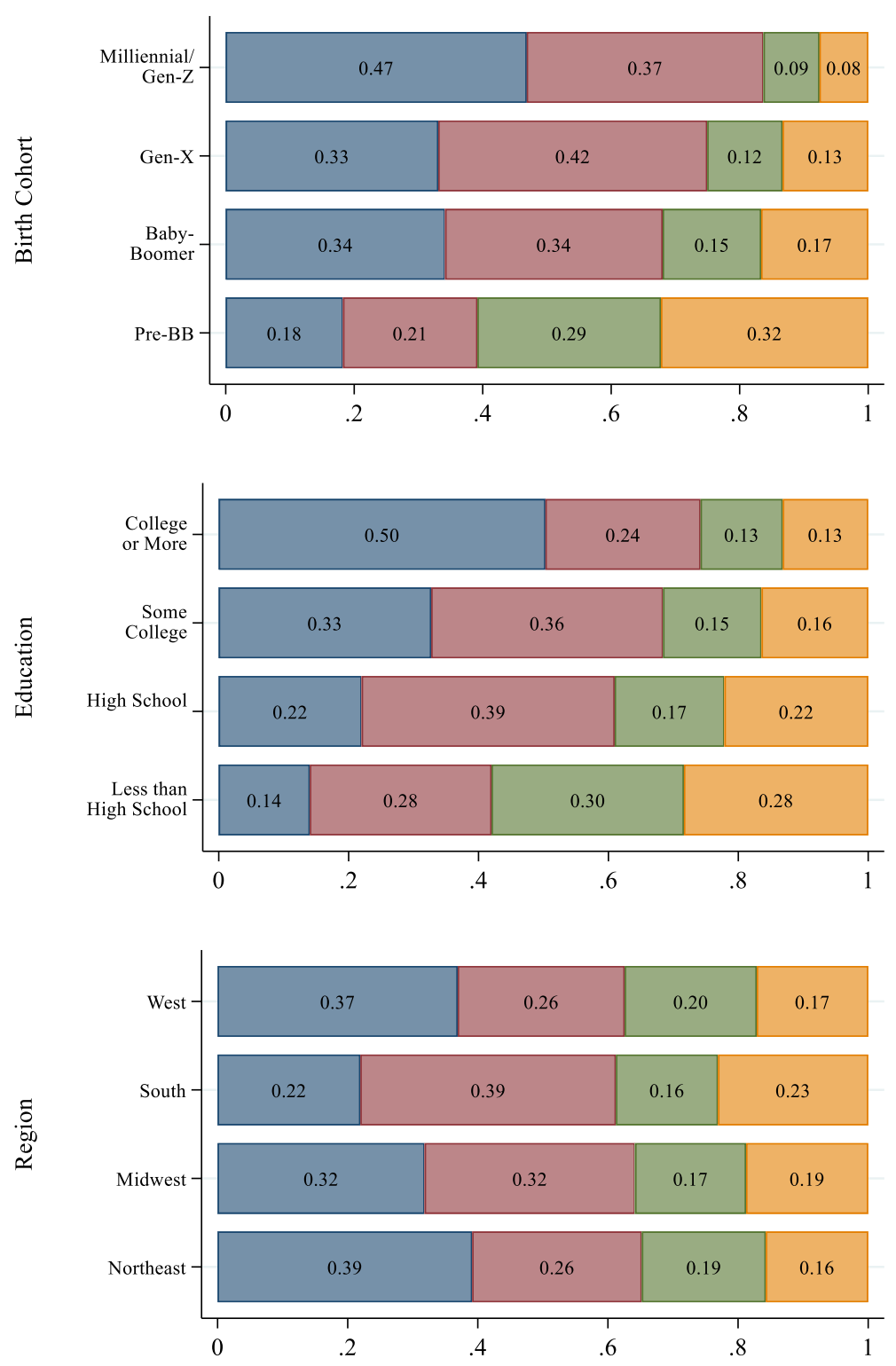
Racial Struct./
Gender Egal.
New Racialism/
Gender Egal.
Racial Struct./
Gender Ambiv.
New Racialism/
Gender Trad.

Note: Probabilities of latent class membership calculated from multinomial logistic regression model using ML-based correction method (Bakk et al. 2013; Vermunt 2010). Full results reported in Table A1. 
Figure 5. Probabilities of Latent Class Membership by Respondent Social Class and Religiosity
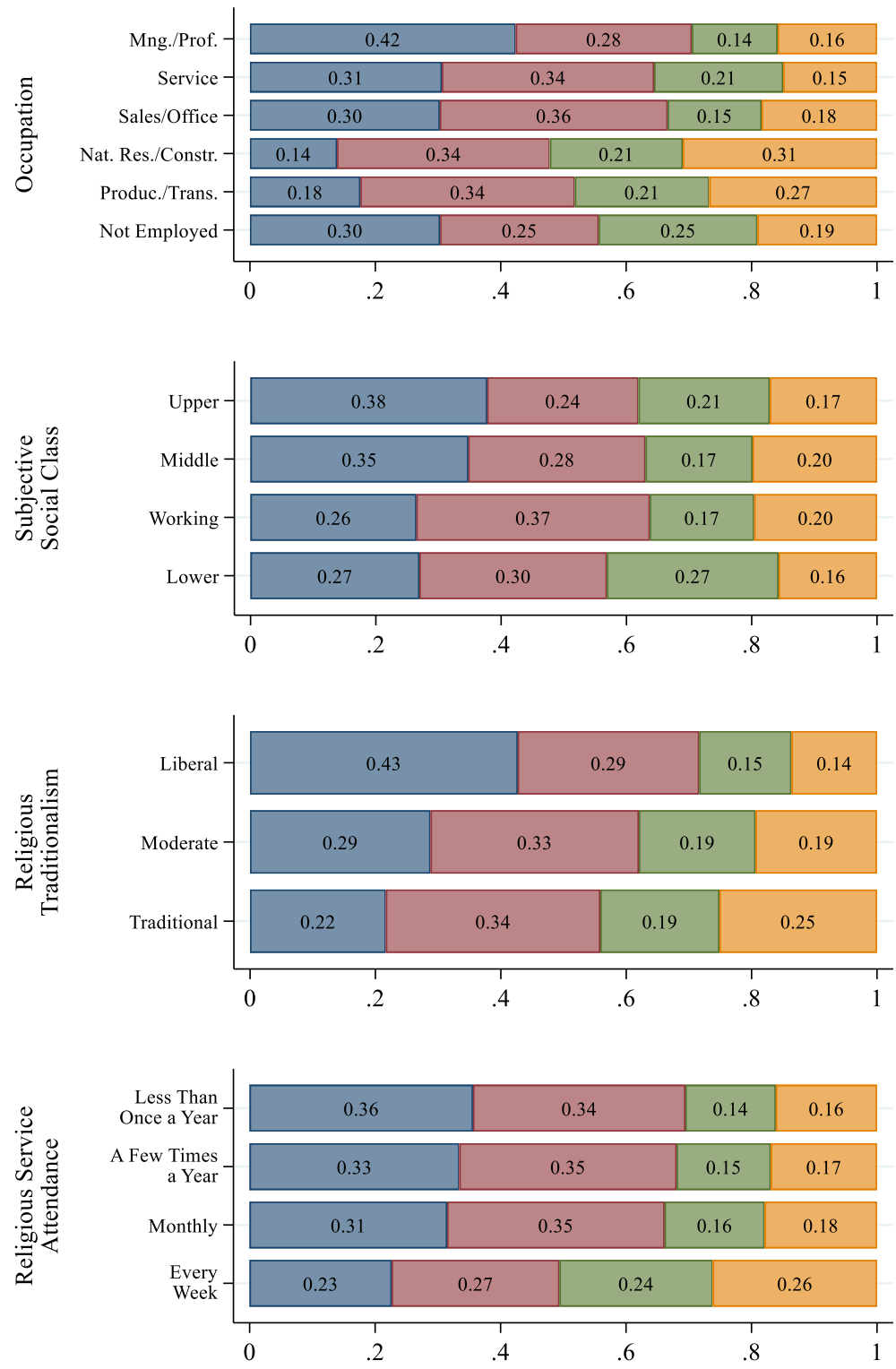
Racial Struct./
New Racialism/
Gender Egal.
Racial Struct./
New Racialism/
Gender Egal.
Gender Ambiv.
Gender Trad.

Note: Probabilities of latent class membership calculated from multinomial logistic regression model using ML-based correction method (Bakk et al. 2013; Vermunt 2010). Full results reported in Table A1. 
In comparison to the two unified progressive and regressive racial/gender attitude configurations, new racialist/gender egalitarian views were more prevalent among those selfidentifying as working-class, those who held a high school or some college education, and those belonging to Baby-Boomer or Gen-X birth cohorts. These views were also more common in the South than other regions of the U.S. Religion played a smaller role than other respondent characteristics, although there is some evidence that those attending religious services every week were less likely to hold new racialist/gender egalitarian views and more likely to possess racial structuralist/gender ambivalent or new racialist/gender traditional attitudes in comparison to those attending religious services less frequently.

Predictors of racial structuralist/gender ambivalent attitudes were primarily those reflecting lower-social class status. Respondents self-identifying as lower-class, those not employed, and those with less than a high school education were the most likely to hold racial structuralist/gender ambivalent views. We also found evidence that weekly attendance at religious services is associated with these attitudes, and that racial structuralist/gender ambivalent perspectives were more common among Pre-Baby Boomers.

Our analysis of additional respondent characteristics associated with racial/gender attitudinal configurations suggests that there are a variety of mechanisms motivating these views. Consistent with previous research, birth cohort and educational differences are strong predictors of racial/gender attitudes (Hunt 2007; Scarborough et al. 2019), followed by religiosity and social class (Bobo and Kluegel 1993; Schnabel 2016). Significant regional differences were observed, but primarily between the South and the rest of the U.S.- - higher levels of new racialism occurred alongside both gender egalitarianism and gender traditionalism in this region than any other. 
Although Figures 4 and 5 highlight several predictors of attitudinal configurations, none distinguish latent class membership to a larger extent than respondent race/gender (reported in Figure 3). For example, our results indicate the virtual absence of new racialist/gender traditional views among Black women, while these views were predicted to occur, at least to some extent, across all other respondent characteristics. These findings underscore a central tenet of intersectional theory: Individuals' structural position within intersecting social systems, such as race and gender, shape their standpoint and perspective (Collins 2008; King 1988). While additional respondent characteristics related to birth cohort, education, social class, and religiosity play a meaningful role in individuals' attitudes, our findings indicate that the experience of respondents' simultaneous race and gender identity is central in shaping how they perceive racial disparities and their expectations for women and men. Respondents in positions disadvantaged from systems of racism and sexism, namely Black women, most commonly hold views that challenge these structures of power, whereas those in positions advantaged from these systems, namely White men, are the most likely to possess views that sustain them.

\section{DISCUSSION}

We used latent class analysis to identify the interrelated ways that racial and gender attitudes are configured, how they have changed over time, and how they varied by respondent characteristics. Four dominant configurations of racial/gender attitudes emerged. Two of these attitudinal groups had unified views across race and gender: New racialist/gender traditionals held universally regressive opinions, whereas racial structuralist/gender egalitarians held corresponding progressive views. The two remaining classes held divergent racial and gender attitudes. The first was among those with new racialist and gender egalitarian beliefs, indicating that gender egalitarian attitudes are not necessarily viewed as incongruent with new racialist 
perspectives. In fact, those with gender egalitarian perspectives were just as likely to hold new racialist attitudes as racial structuralist views. The other group was racial structuralist/gender ambivalents who had progressive views on race attributing racial disparities to structural conditions, while also holding ambivalent perspectives on gender that supported women's public sphere participation but endorsed conventional gendered behavior within families. Among those with racial structuralist perspectives, respondents were almost twice as likely to hold gender egalitarian attitudes than to hold gender ambivalent views.

These intersections of racial and gender attitudes provide new insight into the cultural meanings attached to ideologies of race and gender, particularly when viewed over time and across respondent characteristics. Examining change over the past four decades, we found a growing prevalence of new racialist/gender egalitarian attitudes, particularly from 1977 through 2014, suggesting that the increase in gender egalitarianism during this period was largely facilitated through the incorporation of new racialist views. Racial structuralist/gender egalitarian attitudes have also become more common since 1977, but gains have fluctuated. Still, growth in this perspective has been steady since 2012, and by 2016, it became the most common attitudinal configuration. These findings suggest a growing alignment of racial structuralism and gender egalitarianism in recent years, likely reflective of increasing public attention to the incorporation of intersectional principles within highly visible social movements such as Black Lives Matter. Our study was not designed to test whether these longitudinal trends are due to period effects, cohort replacement, or within-individual attitudinal change. However, the observed differences in attitudes between Pre-Baby Boomer, Baby Boomer, Gen-X, and Millennial/Gen-Z birth cohorts is consistent with previous research showing that cohort replacement plays a substantial role in cultural change (Kiley and Vaisey 2020). 
In addition to birth cohort, our results revealed that education, region, social class, and religiosity are important predictors of racial/gender attitudes. Yet, none of these characteristics distinguished attitudes to as large an extent as respondents' race and gender identity. New racialism and gender egalitarianism appear to have coalesced particularly among White men and White women who were most likely to hold these seemingly contradictory attitudes. White men more readily embraced gender egalitarianism than racial structuralism, whereas White women most commonly possess new racialist views alongside gender egalitarian ones. In contrast, both Black women and Black men most commonly held racial structuralist/gender egalitarian attitudes. Notably, Black men more readily incorporated gender egalitarianism alongside racial structuralism, even though their specific interests may be advanced through supporting gender ambivalence or traditionalism.

Why are racial/gender attitudes more likely to align across race group-interest than gender group-interest? This question highlights important differences between the ways gender and race operate as social structures. We argue these findings reflect stronger bonds on the basis of race over gender. In particular, the intimacy of gender relations as experienced through different-gender coupling is more likely to facilitate bonds among individuals who occupy different structural positions on the basis of gender. Race as a social structure, meanwhile, contains a highly pervasive physical-geographic component that segregates individuals of different race groups (Jackman 1994). While not universal, racial residential segregation and the low percentage of interracial marriages and families means that households are mostly racially homogenous (Bonilla-Silva 2014; Omi and Winant 2014; Wang 2015). This makes it more difficult to form bonds on the basis of gender across racial groups. 
Although structures of race and gender shape the attitudes of both Whites and African Americans to similarly align by race group-interest over gender group-interest, we argue that there are distinct mechanisms driving these patterns for each. The intimacy characterizing gender as a social structure means that bonds between White men and women may contribute to processes of resource hoarding (Jackman 1994; Omi and Winant 2014). White men's combination of new racialism and gender egalitarianism supports White women's opportunities in the service of garnering more resources for their households. From this perspective, White men's espousal of gender egalitarianism is rooted not in benevolent coalition, but paternalistic self-interest in the realization that there is more to gain by endorsing White women's gender equality (Jackman 1994). This is supported by evidence that Whites have more readily embraced gender equality in employment than in the home, where men retain power over allocations of time and financial resources (Kane 2000; Scarborough et al. 2019). By incorporating new racialism alongside gender egalitarianism, White men do not risk the potential loss of power or resources beyond their households, as could occur with more universal support for gender equality extending to Black women with whom they are less commonly partnered (Wang 2015). A key fulcrum in this mechanism is the intersection of heterosexuality which facilitates gendered intimacy between women and men that creates the context for White women's gains in the public sphere to align with White men's self-interest (Ferguson 2003; Rubin 1975; Ward 2020). Viewing White men's gender attitudes alongside their co-occurrence with racial attitudes reveals that increasing gender egalitarianism among this group during recent decades may not be the sign of progress many have interpreted it as. Instead, when combined with new racialist beliefs, White men's espousal of gender egalitarianism serves their interests at the advantaged intersection of race and gender social structures. 
In contrast to motives of resource hoarding among Whites, we contend that patterns of race group-interest over gender group-interest among African Americans reflect coalitions facilitated by intimacy fostered in the shared context of spatial separation from Whites. This interpretation is consistent with Jackman's (1994) argument that although spatial segregation constitutes a powerful mechanism sustaining racial inequality, it is also more conducive to dissent on the part of subordinate groups because dominants have less direct social control in segregated settings (see also Hunter and Robinson 2018; Pattillo 2010). From this vantage, Black men's gender egalitarianism is rooted not in self-interest (as among White men), but rather as an effective and necessary coalition to challenge structures of racial inequality.

\section{Limitations and Future Directions}

Our findings shed light on the intersection of racial and gender attitudes over the past 40 years. There are, however, important limitations and scope conditions to this study. As noted previously, the survey items we analyzed were framed in a unidimensional fashion that assumed respondent racial attitudes did not vary when directed across gender and that respondent gender attitudes did not differ depending on their application toward various race groups. Our reliance on longitudinal data prevented us from addressing these concerns, although ongoing and future data collection efforts may further integrate intersectional framing into question design. Inherent to attitudinal research with diverse samples, our analysis also implicitly assumes that survey questions are interpreted similarly across respondents. However, racial and gender attitude items may be particularly susceptible to varying interpretations across individuals' race and gender identity. For example, expressions of new racialist views may have very different meanings and implications when held by Black and White respondents. Therefore, we stress that the scope of 
our findings are limited to the expressed attitudes of respondents, while their more complicated foundations are left to theoretical interpretation and future research.

Two additional limitations lend themselves to research agendas that would further advance our findings. First, we did not analyze the relationship between racial/gender attitudes and policy support, a topic that has been a major feature of attitudinal research (Bolzendahl and Myers 2004; Tuch and Hughes 2011). It is possible that considering the intersection of racial and gender attitudes may reveal that a large source of opposition to racial policies, for example, comes from those who hold liberal perspectives toward gender, but also espouse new racialist attitudes on race. Second, we did not examine attitudes among Asian or Latinx respondents because these individuals were not identified in the GSS until the late 1990s. Existing research suggests that the racial and gender attitudes of these two groups are more similar to African Americans than Whites (Sanchez 2008; Zheng 2019). Then again, other studies highlight significant heterogeneity of views within Asian and Latinx communities (Oliver 2015). Examining the simultaneity of racial and gender attitudes among Asians and Latinxs may add further insight to within-group variation, as well as contribute additional details on the role of racial group-interest.

\section{Conclusion}

Although the growing confluence of new racialist and gender egalitarian attitudes characterizes most of the period we analyzed, trends from recent years indicate that individuals increasingly hold both racial structuralist and gender egalitarian attitudes. Since 2016, racial structuralist/gender egalitarian views have been the most common, suggesting that racial structuralism and gender egalitarianism appear to be more universally unifying. The mainstreaming of intersectional principles in public discourse and within social movements such 
as Black Lives Matter may have successfully highlighted the complex intersections of race and gender equity, stressing the need to be inclusive of each other rather than independent. We are hopeful that these trends will continue in the future as the discursive power of intersectionality may be used to advance social equity across multiple dimensions. 


\section{NOTES}

${ }^{1}$ Despite a decline in traditional biological racism, genetic testing (Roth and Ivemark 2018) and the rise of racial scientism (Saini 2019) point to the continuance of biological understandings of race.

${ }^{2}$ We follow Krysan (2000) in using the term new racism (which we refer to as new racialism to be applicable across race) as an umbrella concept summarizing various forms of racial ideology rooted in individualist explanations of inequality. Although additional theories have been used to highlight more specific aspects of new racialism, such as colorblind racism (Bonilla-Silva 2014) and white racial frames (Feagin 2009), our aim is not to differentiate between specific ideologies. Instead, we take a broader view on shifting racial attitudes over time and their relation to gender attitudes.

${ }^{3}$ Contradictory gender attitudes have also been described using numerous terms, such as egalitarian familism (Knight and Brinton 2017), gender essentialism (Cotter et al. 2011), and intensive parenting (Grunow et al. 2018). We use the term ambivalence because it provides a more general label describing the possession of contradictory attitudes.

${ }^{4}$ WRKWAYUP is an additional variable in the GSS previously used as an indicator of new racialist attitudes (Krysan 2000). We omitted this variable in our analysis because it was not asked from 1977 through 1993 and was therefore missing for 33.7 percent of our sample. To test whether our results are sensitive to the omission of this variable, we conducted LCA that included WRKWAYUP as an additional indicator using a restricted sample that included only respondents non-missing on this item. Results (reported in the online supplement) were substantively similar, suggesting the omission of this item does not affect our findings.

${ }^{5}$ We use the weighting variable WTSSALL provided by the GSS. 
${ }^{6}$ Syntax used in analyses are available on the corresponding author's OSF web page (https://osf.io/6kyn8/).

${ }^{7}$ We also performed all analyses using modal assignment of respondents to classes. All substantive findings remained unchanged from the results presented here using proportional assignment.

${ }^{8}$ Although our provisional use of binary gender categories follows conventional methods, we note the possibility for important intersections of racial/gender attitudes among those who do not identify within binary cisgender categories.

${ }^{9}$ Generations are defined according to Dimock (2019) and commonly used in previous research (Scarborough et al. 2019; Shu and Meagher 2018). Our sample included fewer than 100 respondents from Generation Z (born after 1996). Therefore, we combined this cohort with Millennials. Although these four general birth cohort categories are often used in existing research, studies focusing explicitly on cohort effects have also applied more detailed categories that define birth cohorts according to specific birth year or five-year increments (Vaisey and Lizardo 2016; Shu and Meagher 2018). Because our purpose in this study does not include a direct examination of cohort effects, we use the most general measures of birth cohorts to provide more interpretable trends in the marginal differences between aggregate groups.

${ }^{10}$ Regions are defined by the GSS according to U.S. Census classifications. The Northeast includes Connecticut, Maine, Massachusetts, New Hampshire, New Jersey, New York, Pennsylvania, Rhode Island, and Vermont. The Midwest includes Illinois, Indiana, Iowa, Kansas, Michigan, Minnesota, Missouri, Nebraska, North Dakota, Ohio, South Dakota, and Wisconsin. The South includes Alabama, Arkansas, Delaware, the District of Columbia, 
Florida, Georgia, Kentucky, Louisiana, Maryland, Mississippi, North Carolina, Oklahoma, South Carolina, Tennessee, Texas, Virginia, and West Virginia. The West includes Alaska, Arizona, California, Colorado, Hawaii, Idaho, Montana, Nevada, New Mexico, Oregon, Utah, Washington, and Wyoming.

${ }^{11}$ Our use of broad occupational groups is likely to provide conservative estimates for social class differences, as previous research suggests that detailed occupations representing microclasses better capture important social class dimensions (Weeden and Grusky 2005).

${ }^{12}$ We measure religious traditionalism using the FUND variable in the GSS. In each survey year, the GSS codes respondents' religious traditionalism based on characteristics of their reported religion. Traditional or fundamentalist religions, such as Southern Baptists, are characterized by the direct interpretation of the Bible or religious texts, a belief in the return of Christ or religious savior, and efforts to convert others to their religion. Respondents coded liberal on this item report having no religion or hold a religion such as United Methodist that focus more on the natural world, endorse science over religious doctrine, and view the Bible and religious text as metaphorical. Moderate religions include Lutherans and exist between traditional and liberal beliefs. Respondents holding these beliefs may reject the anti-science approach of traditional religions while still endorsing religious beliefs and practices. Further information on these coding schemes is documented by Smith (1987).

13 The following pairs of variables were specified to covary in relaxing the assumption of conditional independence for the five-class model: FEFAM and RACDIF4; FECHLD and RACDIF4; FEFAM and FEPOL; FEPRESCH and RACDIF3; FEPOL and RACDIF4; RACDIF4 and RACDIF2; FEPRESCH and FEPOL; FEFAM and RACDIF2; FECHLD and FEPOL; FEPOL and RACDIF2; FECHLD and RACDIF2; and RACDIF3 and RACDIF2. 
14 The following pairs of variables were specified to covary in our selected four-class LCA model: RACDIF1 and RACDIF2; RACDIF2 and RACDIF4; FEPOL and FEFAM; FEPOL and FECHLD; FEFAM and RACDIF2; FEFAM and RACDIF4; FEPOL and RACDIF2; FEPOL and RACDIF4; FECHLD and RACDIF2; FEFAM and RACDIF3; and FECHLD and RACDIF4.

15 The sample size for Black women and Black men respondents was low (fewer than 100) for many years. Therefore, we do not present longitudinal trends by race/gender subgroups because annual estimates are imprecise. Preliminary analysis using the data with low cell counts does suggest that trends differ by race and gender, with Black women and men showing consistently higher levels of racial structuralist/gender egalitarian attitudes. 
Intersection of Racial and Gender Attitudes

\section{APPENDIX}

Table A1. Full Results, Multinomial Logistic Regression Model Predicting Latent Class Membership

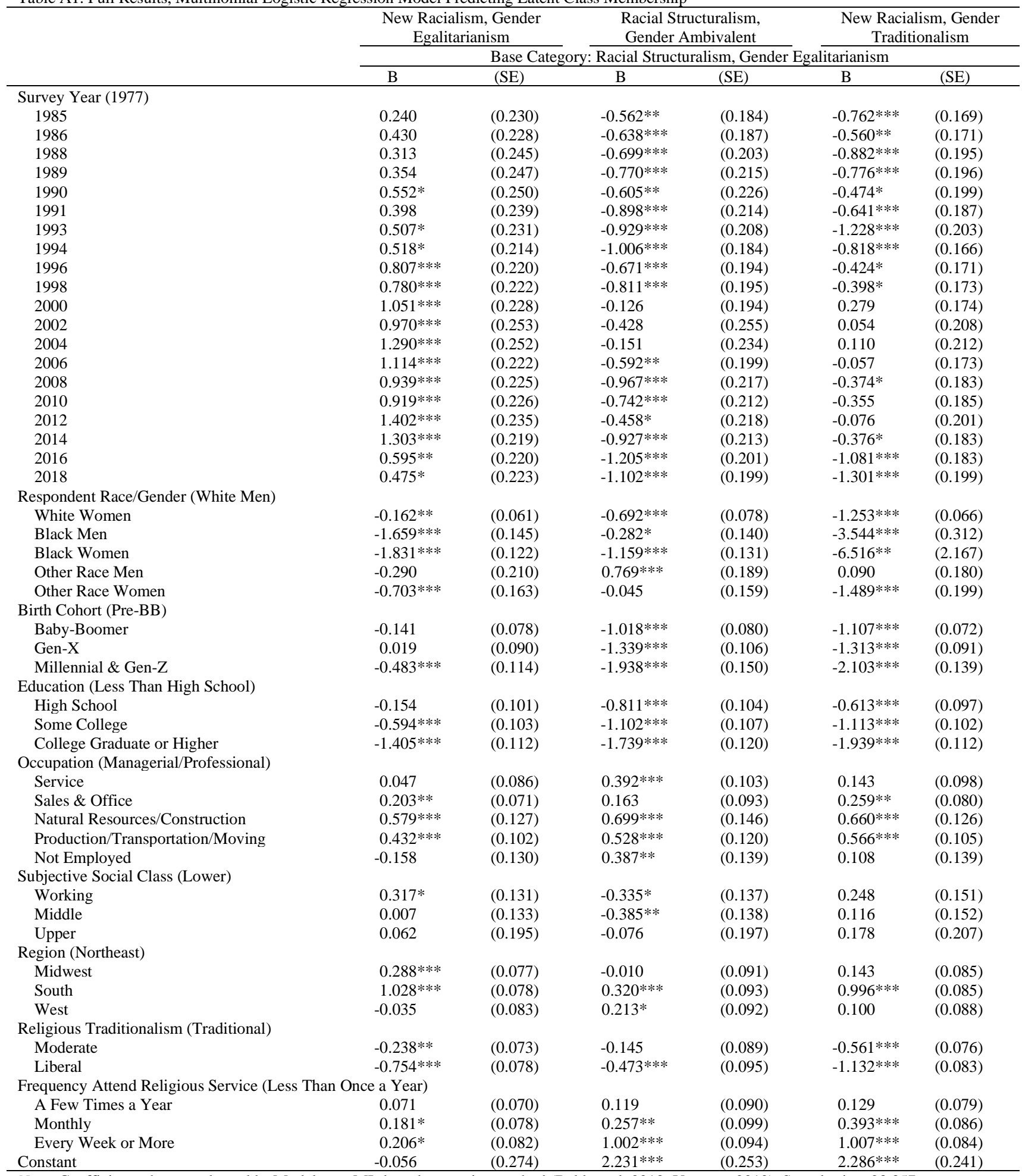

Note: Coefficients shown as log odds. Model uses ML-based correction method (Bakk et al. 2013; Vermunt 2010). Sample size: 23,357. 


\section{REFERENCES}

Apostle, Richard A., Charles Y. Glock, Thomas Piazza, and Marijean Suelzle. 1983. The Anatomy of Racial Attitudes. Berkeley, CA: University of California Press.

Barnett, Bernice M. 1993. "Invisible Southern Black Women Leaders in the Civil Rights Movement: The Triple Constraints of Gender, Race, and Class.” Gender \& Society 7(2):162-82.

Bakk, Zsuzsa, Fetene B. Tekle, and Jeroen K. Vermunt. 2013. "Estimating the Association between Latent Class Membership and External Variables Using Bias-Adjusted ThreeStep Approaches." Sociological Methodology 43(1): 272-311.

Blow, Charles. 2020. "Exit Polls Point to the Power of White Patriarchy." New York Times. Retrieved November 10, 2020 (https://nyti.ms/3jZZGyn).

Bobo, Lawrence. 1988. "Group Conflict, Prejudice, and the Paradox of Contemporary Racial Attitudes.” Pp. 85-114 in Eliminating Racism: Profiles in Controversy, Perspectives in Social Psychology, edited by Phyllis A. Katz and Dalmas A. Taylor. Boston, MA: Springer.

Bobo, Lawrence, and James R. Kluegel. 1993. “Opposition to Race-Targeting: Self-Interest, Stratification Ideology, or Racial Attitudes?” American Sociological Review 58(4): 44364.

Bobo, Lawrence D., James R. Kluegel, and Ryan A. Smith. 1997. "Laissez-Faire Racism: The Crystallization of a Kinder, Gentler, Antiblack Ideology.” Pp. 15-42 in Racial Attitudes in the 1990s: Continuity and Change, edited by Steven A. Tuch and Jack K. Martin. Westport, CT: Praeger.

Bolzendahl, Catherine I., and Daniel J. Myers. 2004. "Feminist Attitudes and Support for Gender Equality: Opinion Change in Women and Men, 1974-1998." Social Forces 83(2):759-89.

Bonikowski, Bart, and Paul DiMaggio. 2016. "Varieties of American Popular Nationalism." American Sociological Review 81(5): 949-80.

Bonilla-Silva, Eduardo. 1997. "Rethinking Racism: Toward a Structural Interpretation." American Sociological Review 62(3):465-80.

Bonilla-Silva, Eduardo. 2014. Racism without Racists: Color-Blind Racism and the Persistence of Racial Inequality in America. Lanham, MD: Rowman \& Littlefield Publishers.

Bowleg, Lisa. 2008. "When Black + Lesbian + Woman $\neq$ Black Lesbian Woman: The Methodological Challenges of Qualitative and Quantitative Intersectionality Research." Sex Roles 59(5):312-25.

Brewer, Sierra, and Lauren Dundes. 2018. "Concerned, Meet Terrified: Intersectional Feminism and the Women's March.” Women's Studies International Forum 69:49-55. 
Buchanan, Larry, Quoctrung Bui, and Jugal Patel. 2020. "Black Lives Matter May Be the Largest Movement in U.S. History.” New York Times. Retrieved October 26, 2020 (https://nyti.ms/2ZqRyOU).

Carter, J. Scott, Mamadi Corra, and Sarah Okorie. 2018. "Seeing Discrimination: Does Acknowledging Structural Determinants of Inequality Impact Support for the Use of Force by Police among Whites?” Western Journal of Black Studies 42(1/2):18-28.

Chavez, Koji, and Adia Harvey Wingfield. 2018. "Racializing Gendered Interactions." Pp. 18597 in Handbook of the Sociology of Gender, Handbooks of Sociology and Social Research, edited by Barbara Risman, Carissa Froyum, and William Scarborough. New York: Springer.

Cho, Sumi, Kimberlé Williams Crenshaw, and Leslie McCall. 2013. "Toward a Field of Intersectionality Studies: Theory, Applications, and Praxis." Signs: Journal of Women in Culture and Society 38(4):785-810.

Cohen, Cathy J. 2010. Democracy Remixed: Black Youth and the Future of American Politics. Oxford, UK: Oxford University Press.

Collins, Patricia Hill. 2008. Black Feminist Thought: Knowledge, Consciousness, and the Politics of Empowerment. New York: Routledge.

Cotter, David, Joan M. Hermsen, and Reeve Vanneman. 2011. "The End of the Gender Revolution? Gender Role Attitudes from 1977 to 2008.” American Journal of Sociology 117(1):259-89.

Crenshaw, Kimberlé Williams. 1989. "Demarginalizing the Intersection of Race and Sex: A Black Feminist Critique of Antidiscrimination Doctrine, Feminist Theory and Antiracist Politics." University of Chicago Legal Forum 8: 139-167.

Davis, Angela Y. 1983. Women, Race, \& Class. New York: Vintage.

Dawson, Michael C. 2001. Black Visions: The Roots of Contemporary African-American Political Ideologies. Chicago, IL: University of Chicago Press.

Dernberger, Brittany N., and Joanna R. Pepin. 2020. "Gender Flexibility, but Not Equality: Young Adults' Division of Labor Preferences.” Sociological Science 7:36-56.

Dimock, Michael. 2019. "Defining Generations: Where Millennials End and Generation Z Begins." Pew Research Center. Retrieved October 15, 2020 (https://www.pewresearch.org/fact-tank/2019/01/17/where-millennials-end-andgeneration-z-begins/).

England, Paula, Andrew Levine, and Emma Mishel. 2020. "Progress toward Gender Equality in the United States Has Slowed or Stalled." Proceedings of the National Academy of Sciences 117(13): 6990-97. 
Feagin, Joe R. 2009. The White Racial Frame: Centuries of Racial Framing and CounterFraming. New York: Routledge.

Feldman, Stanley, and John Zaller. 1992. "The Political Culture of Ambivalence: Ideological Responses to the Welfare State.” American Journal of Political Science 36 (1): 268-307.

Ferguson, Roderick A. 2003. Aberrations In Black: Toward A Queer Of Color Critique. Minneapolis, MN: University of Minnesota Press.

Fisher, Dana R., Dawn M. Dow, and Rashawn Ray. 2017. "Intersectionality Takes It to the Streets: Mobilizing across Diverse Interests for the Women's March." Science Advances 3(9): 1-8.

Forman, Tyrone. 2004. "Color-Blind Racism and Racial Indifference: The Role of Racial Apathy in Facilitating Enduring Inequalities." Pp. 43-66 in The Changing Terrain of Race and Ethnicity, edited by Maria Krysan and Amanda E. Lewis. New York: Sage.

Forman, Tyrone A., and Amanda E. Lewis. 2006. "Racial Apathy and Hurricane Katrina: The Social Anatomy of Prejudice in the Post-Civil Rights Era." Du Bois Review: Social Science Research on Race 3(1):175-202.

Garcia, Lorena. 2012. Respect Yourself, Protect Yourself: Latina Girls and Sexual Identity. New York: New York University Press.

Grunow, Daniela, Katia Begall, and Sandra Buchler. 2018. "Gender Ideologies in Europe: A Multidimensional Framework.” Journal of Marriage and the Family 80(1):42-60.

Hamilton, Laura T., Elizabeth A. Armstrong, J. Lotus Seeley, and Elizabeth M. Armstrong. 2019. "Hegemonic Femininities and Intersectional Domination." Sociological Theory 37(4):315-41.

Harnois, Catherine E. 2013. Feminist Measures in Survey Research. New York: Sage.

Hochschild, Jennifer L. 2006. "Ambivalence About Equality in the United States or, Did Tocqueville Get It Wrong and Why Does That Matter?” Social Justice Research 19(1): 43-62.

hooks, bell. 1981. Ain't I a Woman: Black Women and Feminism. Boston, MA: South End Press.

Hughes, Michael. 1997. "Symbolic Racism, Old-Fashioned Racism, and Whites' Opposition to Affirmative Action.” Pp. 45-75 in Racial Attitudes in the 1990s: Continuity and Change, edited by Steven A. Tuch and Jack K. Martin. Westport, CT: Praeger.

Hunt, Matthew O. 2007. "African American, Hispanic, and White Beliefs about Black/White Inequality, 1977-2004.” American Sociological Review 72(3):390-415.

Hunter, Marcus Anthony, and Zandria Robinson. 2018. Chocolate Cities: The Black Map of American Life. Oakland, CA: University of California Press. 
Jacobs, Harriet. 1987. Incidents in the Life of a Slave Girl, Written by Herself. Cambridge, MA: Harvard University Press.

Jackman, Mary R. 1994. The Velvet Glove: Paternalism and Conflict in Gender, Class, and Race Relations. Berkeley, CA: University of California Press.

Janssen, Jeroen H. M., Saskia van Laar, Mark J. de Rooij, Jouni Kuha, and Zsuzsa Bakk. 2019. "The Detection and Modeling of Direct Effects in Latent Class Analysis." Structural Equation Modeling: A Multidisciplinary Journal 26(2): 280-90.

Kane, Emily W. 2000. "Racial and Ethnic Variations in Gender-Related Attitudes." Annual Review of Sociology 26(1): 419-39.

Ken, Ivy, and Allison Suppan Helmuth. 2021. "Not Additive, Not Defined: Mutual Constitution in Feminist Intersectional Studies.” Feminist Theory doi: 10.1177/1464700120987393.

Kiley, Kevin, and Stephen Vaisey. 2020. "Measuring Stability and Change in Personal Culture Using Panel Data.” American Sociological Review 85(3): 477-506.

Kinder, Donald R., and Lynn M. Sanders. 1996. Divided by Color: Racial Politics and Democratic Ideals. Chicago, IL: University of Chicago Press.

King, Deborah K. 1988. "Multiple Jeopardy, Multiple Consciousness: The Context of a Black Feminist Ideology.” Signs 14(1):42-72.

Kluegel, James R., and Eliot R. Smith. 1986. Beliefs about Inequality: Americans' Views of What Is and What Ought to Be. New York: Routledge.

Knight, Carly R., and Mary C. Brinton. 2017. "One Egalitarianism or Several? Two Decades of Gender-Role Attitude Change in Europe.” American Journal of Sociology 122(5):14851532.

Kollenburg, Geert H. van, Joris Mulder, and Jeroen K. Vermunt. 2015. "Assessing Model Fit in Latent Class Analysis When Asymptotics Do Not Hold.” Methodology 11(2): 65-79.

Krysan, Maria. 1998. "Privacy and the Expression of White Racial Attitudes: A Comparison Across Three Contexts." The Public Opinion Quarterly 62(4):506-44.

Krysan, Maria. 2000. "Prejudice, Politics, and Public Opinion: Understanding the Sources of Racial Policy Attitudes.” Annual Review of Sociology 26(1):135-68.

Lagos, Danya, and D'Lane Compton. 2021. "Evaluating the Use of Two-Step Gender Identity Measures in the 2018 General Social Survey.” Demography 58(2): 763-772.

McConahay, John B. 1986. "Modern Racism, Ambivalence, and the Modern Racism Scale." Pp. 91-124 in Prejudice, Discrimination, and Racism, edited by John F. Dovidio and Samuel L. Gaertner. Orlando, FL: Academic Press. 
McLachlan, Geoffrey J., and David Peel. 2004. Finite Mixture Models. Hoboken, NJ: John Wiley \& Sons.

Meagher, Kelsey, and Xiaoling Shu. 2019. "Trends in U.S. Gender Attitudes, 1977 to 2018 : Gender and Educational Disparities.” Socius doi: 10.1177/2378023119851692.

Moberg, Sarah Patton, Maria Krysan, and Deanna Christianson. 2019. "Racial Attitudes in America." Public Opinion Quarterly 83(2):450-71.

Nagelkerke, Erwin, Daniel L. Oberski, and Jeroen K. Vermunt. 2016. "Goodness-of-Fit of Multilevel Latent Class Models for Categorical Data.” Sociological Methodology 46(1): 252-82.

Nash, Jennifer C. 2008. “Re-Thinking Intersectionality.” Feminist Review 89(1):1-15.

Nylund, Karen L., Tihomir Asparouhov, and Bengt O. Muthén. 2007. "Deciding on the Number of Classes in Latent Class Analysis and Growth Mixture Modeling: A Monte Carlo Simulation Study." Structural Equation Modeling: A Multidisciplinary Journal 14(4):535-69.

Oliver, J. Eric. 2010. The Paradoxes of Integration: Race, Neighborhood, and Civic Life in Multiethnic America. Chicago, IL: University of Chicago Press.

Omi, Michael, and Howard Winant. 2014. Racial Formation in the United States. New York: Routledge.

Pattillo, Mary. 2010. Black on the Block: The Politics of Race and Class in the City. Chicago, IL: University of Chicago Press.

Pepin, Joanna R., and David A. Cotter. 2018. "Separating Spheres? Diverging Trends in Youth's Gender Attitudes About Work and Family." Journal of Marriage and Family 80(1):7-24.

Pettigrew, Thomas, and Roel Meertens. 1995. "Subtle and Blatant Prejudice in Western Europe." European Journal of Social Psychology 25(1):57-75.

Ransby, Barbara. 2018. Making All Black Lives Matter: Reimagining Freedom in the TwentyFirst Century. Berkeley, CA: University of California Press.

Risman, Barbara J. 2018. Where the Millennials Will Take Us: A New Generation Wrestles with the Gender Structure. Oxford, UK: Oxford University Press.

Robinson, Zandria F. 2018. "Intersectionality and Gender Theory." Pp. 69-80 in Handbook of the Sociology of Gender, edited by Barbara Risman, Carissa Froyum, and William Scarborough. New York: Springer Press.

Rogers, Katie. 2016. "White Women Helped Elect Donald Trump.” New York Times. Retrieved November 10, 2020 (https://nyti.ms/2eDXpXO). 
Roos, J. Micah, Michael Hughes, and Ashley V. Reichelmann. 2019. “A Puzzle of Racial Attitudes: A Measurement Analysis of Racial Attitudes and Policy Indicators." Socius 5: $1-14$.

Roth, Wendy D., and Biorn Ivemark. 2018. "Genetic Options: The Impact of Genetic Ancestry Testing on Consumers' Racial and Ethnic Identities.” American Journal of Sociology 124(1):150-84.

Rubin, Gayle. 1975. “The Traffic in Women: Notes on the 'Political Economy' of Sex.” Pp. 155170 in Toward an Anthropology of Women, edited by Reyna Reiter. New York: Monthly Review Press.

Saini, Angela. 2019. Superior: The Return of Race Science. Boston, MA: Beacon Press.

Sanchez, Gabriel R. 2008. "Latino Group Consciousness and Perceptions of Commonality with African Americans.” Social Science Quarterly 89(2):428-44.

Scarborough, William, and Ray Sin. 2020. "Gendered Places: The Dimensions of Local Gender Norms across the United States." Gender \& Society 34(5): 705-35.

Scarborough, William, Ray Sin, and Barbara Risman. 2019. "Attitudes and the Stalled Gender Revolution: Egalitarianism, Traditionalism, and Ambivalence from 1977 through 2016:" Gender \& Society 33(2): 173-200.

Schnabel, Landon. 2016. "Gender and Homosexuality Attitudes across Religious Groups from the 1970s to 2014: Similarity, Distinction, and Adaptation." Social Science Research 55: $31-47$.

Schreiber, James B. 2017. "Latent Class Analysis: An Example for Reporting Results.” Research in Social and Administrative Pharmacy 13(6): 1196-1201.

Schuman, Howard, Charlotte Steeh, Lawrence D. Bobo, and Maria Krysan. 1998. Racial Attitudes in America: Trends and Interpretations, Revised Edition. Cambridge, Mass: Harvard University Press.

Sears, David, Collette VanLaar, Mary Carillo, and Rick Kosterman. 1997. "Is It Really Racism?: The Origins of White Americans' Opposition to Race-Targeted Policies.” Public Opinion Quarterly 61(1): 16-53.

Shu, Xiaoling, and Kelsey Meagher. 2018. "Beyond the Stalled Gender Revolution: Historical and Cohort Dynamics in Gender Attitudes from 1977 to 2016." Social Forces 96(3):1243-74.

Smith, Candis Watts. 2014. "Shifting From Structural to Individual Attributions of Black Disadvantage: Age, Period, and Cohort Effects on Black Explanations of Racial Disparities." Journal of Black Studies 45(5):432-52. 
Smith, Tom W. 1987. "GSS Methodological Report No. 43: Classifying Protestant Denominations.” Chicago, IL: The National Opinion Research Center.

Smith, Tom W., Davern, Michael, Freese, Jeremy, and Morgan, Stephen. General Social Surveys, 1972-2018 [machine-readable data file] /Principal Investigator, Smith, Tom W.; Co-Principal Investigators, Michael Davern, Jeremy Freese, and Stephen Morgan; Sponsored by National Science Foundation. --NORC ed.-- Chicago: NORC, 2018: NORC at the University of Chicago [producer and distributor]. Data accessed from the GSS Data Explorer website at gssdataexplorer.norc.org.

Sweet, Paige L. 2018. “The Feminist Question in Realism.” Sociological Theory 36(3):221-43.

Taylor, Keeanga-Yamahtta. 2016. From \#BlackLivesMatter to Black Liberation. Chicago, IL: Haymarket Books.

Tuch, Steven, and Michael Hughes. 2011. "Whites' Racial Policy Attitudes in the Twenty-First Century: The Continuing Significance of Racial Resentment." The ANNALS of the American Academy of Political and Social Science 634(1):134-52.

Vermunt, Jeroen K. 2010. "Latent Class Modeling with Covariates: Two Improved Three-Step Approaches." Political Analysis 18(4): 450-69.

Vermunt, Jeroen K., and Jay Magidson. 2013. Latent GOLD 5.0 Upgrade Manual. Belmont, MA: Statistical Innovations Inc.

Virtanen, Simo V., and Leonie Huddy. 1998. "Old-Fashioned Racism and New Forms of Racial Prejudice.” The Journal of Politics 60(2):311-32.

Ward, Jane. 2020. The Tragedy of Heterosexuality. New York: New York University Press.

Wang, Wendy. 2015. “Interracial Marriage: Who Is 'Marrying Out'?” Pew Research Center. Retrieved October 25, 2020 (https://www.pewresearch.org/facttank/2015/06/12/interracial-marriage-who-is-marrying-out/).

Weeden, Kim A., and David B. Grusky. 2005. "The Case for a New Class Map.” American Journal of Sociology 111(1): 141-212.

Wells-Barnett, Ida B. 2018. The Red Record. Frankfurt, DE: Outlook Verlag.

White, Deborah. 2018. “2017 Midwest Sociological Society Presidential Address: Trump's Election, Women's Marches, and the Enduring Quest for Gender Equity in Politics." The Sociological Quarterly 59(1):5-16.

Wilson, Thomas C. 2006. "Whites' Opposition to Affirmative Action: Rejection of Group-Based Preferences as Well as Rejection of Blacks.” Social Forces 85(1):111-20.

Zheng, Bang Quan. 2019. “The Patterns of Asian Americans' Partisan Choice: Policy Preferences and Racial Consciousness.” Social Science Quarterly 100(5):1593-1608. 